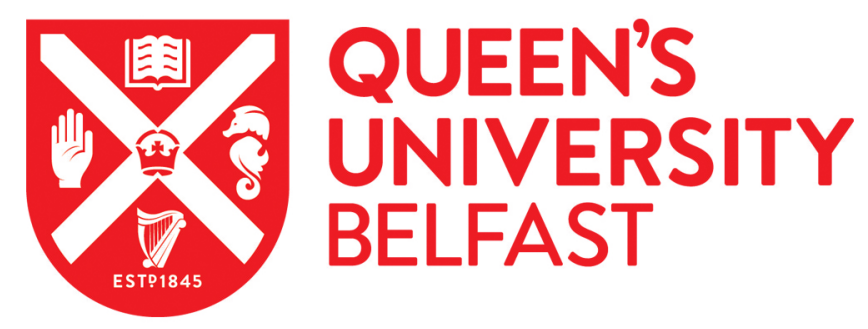

\title{
Influence of nano-clay on rheology, fresh properties of hydration and strength of cement-based mortars
}

Dejaghere, I., Sonebi, M., \& De Schutter, G. (2019). Influence of nano-clay on rheology, fresh properties of hydration and strength of cement-based mortars. Construction and Building Materials, 22, 73-85.

https://doi.org/10.1016/j.conbuildmat.2019.06.111

\section{Published in:}

Construction and Building Materials

\section{Document Version:}

Peer reviewed version

\section{Queen's University Belfast - Research Portal:}

Link to publication record in Queen's University Belfast Research Portal

\section{Publisher rights}

Copyright 2019 Elsevier

This manuscript is distributed under a Creative Commons Attribution-NonCommercial-NoDerivs License

(https://creativecommons.org/licenses/by-nc-nd/4.0/), which permits distribution and reproduction for non-commercial purposes, provided the author and source are cited.

\section{General rights}

Copyright for the publications made accessible via the Queen's University Belfast Research Portal is retained by the author(s) and / or other copyright owners and it is a condition of accessing these publications that users recognise and abide by the legal requirements associated with these rights.

Take down policy

The Research Portal is Queen's institutional repository that provides access to Queen's research output. Every effort has been made to ensure that content in the Research Portal does not infringe any person's rights, or applicable UK laws. If you discover content in the Research Portal that you believe breaches copyright or violates any law, please contact openaccess@qub.ac.uk. 


\title{
Influence of nano-clay on rheology, fresh properties, heat of hydration and strength of cement-based mortars
}

\author{
Ines Dejaeghere ${ }^{1}$, Mohammed Sonebi $^{1 *}$, Geert De Schutter ${ }^{2}$ \\ ${ }^{1}$ School of Natural and Built Environment, Queen's University Belfast, Belfast, Northern \\ Ireland, UK \\ ${ }^{2}$ Magnel Laboratory for Concrete Research, Department of Structural Engineering, Ghent \\ University, Belgium
}

\begin{abstract}
The objective of this research was to optimise the fresh mix properties, rheological parameters, heat of hydration and development of the compressive strength of cement mortars containing nano-clay (nCL) and fly ash (FA). All mixtures were made with water-to-binder ratio (W/B) of 0.40 . The replacement of cement by FA was varied from 5\% to $20 \%$ (by mass of cement), and dosages of superplasticiser (SP) and nCL were varied from $0.6 \%$ to $3 \%$ (by mass of binder), and $0.5 \%$ and $2.5 \%$ (by mass of cement), respectively. The fresh mix properties were evaluated by using mini-slump flow, Marsh cone flow time and Lombardi plate cohesion meter, and induced bleeding. Yield stress and viscosity were determined to analyse the effects on rheology. Variations in hydration kinetics were examined through calorimetry tests. Compressive strength was measured and evaluated at different ages up to 28 days. Dosages of nano-clay, fly ash and superplasticiser were the investigated key parameters. Statistical models and isoresponse curves were used to identify significant trends. Prediction models were developed for mini-slump, Marsh cone, Lombardi plate cohesion meter, heat of hydration, induced bleeding, static and dynamic yield stress, plastic viscosity, and compressive strengths at $1 \mathrm{~d}, 3 \mathrm{~d}, 7 \mathrm{~d}$, and $28 \mathrm{~d}$ as function of nCL, FA, and SP. Optimization of mortar proportioning to fulfil required performance levels in fresh and hardened states was possible by using the predicted models presented in this paper.
\end{abstract}

Keywords: Compressive strength; fly ash; heat of hydration, induced bleeding, nanoclay; superplasticiser; yield stress; plastic viscosity 


\section{Introduction}

Manipulation of structures at nanoscale $(<100 \mathrm{~nm})$ is called nano-modification. It can be used to enhance cement composition. Nanoparticles can accelerate the rate of hydration and improve early-age strength of cement-based materials with supplementary cementitious materials like fly ash [1-3]. Most known nanoparticles are titanium dioxide $\left(\mathrm{TiO}_{2}\right)$, zinc dioxide $\left(\mathrm{ZnO}_{2}\right)$, calcium carbonate $\left(\mathrm{CaCO}_{3}\right)$, nano-silica $(\mathrm{nS})$ and nano-clay (nCL) [4-26].

The effect of nanoparticles on fresh and hardened properties is caused by several simultaneous mechanisms [27]. Firstly, the filler effect, as their small size enables improve microstructure and increase packing density [28]. Secondly, due to nucleation effect they can accelerate cement hydration [29]. The particles act as a highly efficient nucleation sites for silica units that are released from cement particles and for the first Calcium Silicate Hydrate (C-S-H) seeds. Around the additional nucleation site dispersed in the pore solution, the hydration products can also accumulate. When the nanoparticles are well dispersed in the mixture, the C-S-H production can take place in the voids between the grains, with a more compact matrix consequently. Thirdly, there is a chemical or pozzolanic effect with formation of additional C-S-H. Nanoparticles can react with calcium hydroxide, which is formed as a by-product from cement hydration, to construct extra C-S-H. There is a synergy between the acceleration of cement hydration and the pozzolanic effect. The hydration of tricalcium Silicate $\left(\mathrm{C}_{3} \mathrm{~S}\right)$ and dicalcium Silicate $\left(\mathrm{C}_{2} \mathrm{~S}\right)$ forms calcium hydroxide. The hydration rate of $\mathrm{C}_{3} \mathrm{~S}$ is accelerated because the cement hydration is accelerated by the nucleation effect [30, 31]. Therefore, calcium hydroxide release rate is increased, sooner available and favours the pozzolanic effect of nanoparticles. Induction period of cement hydration is shortened and the release of calcium ions quicker with fast consumption due to pozzolanic action [8]. Finally, there could also be a dilution effect in case the cementreplacing powder particles are inert [29].

Small additions of nano-clay (smaller than $1 \%$ by mass of binder) have proven to increase the green strength of self-consolidating concrete directly after casting without significant changes in flowability [21, 22]. On the one hand, the addition of any nanoparticles at constant water content will cause an increase in stiffness because the water demand is raised. It can be a dominant factor, as nano-clay can have a water adsorption of 
$200 \%$ by mass [23]. On the other hand, nano-clay enhances the thixotropic behaviour of cementitious materials [32], which can be noticeable in the development of green strength when the material is at rest [21].

Neaman and Singer [24] showed that an increase in the length to width ratio of nonpurified palygorskite nano-clay particles will increase rheological parameters like viscosity and yield value. This makes the purification process critical to ensure uniform size and shape particles so that variability of the rheology is controlled. Research with kaolinite clay and belite clay showed that in combination with Portland cement, these nano-sized layer silicates do not show pozzolanic reactions. An improvement in strength, durability and acceleration of cement hydration was however noticed, probably linked to nucleation effect and filler effect.

Nano-clay categorized as highly purified magnesium aluminium silicate, Acti-gel, is known to improve the performance of concrete [30, 31]. Most aluminium silicates used commercially, are created by the dry method. However, Acti-gel is created by the wet process, which mechanically removes impurities and grit. Acti-gel is negatively charged along its axis and positively on the ends, which stimulates gel formation to connect the microstructure of cement-based materials. Addition of Acti-gel in cement-based materials is thixotropic with an increasing value at higher dosages of Acti-gel [32, 33]. A card-house network microstructure is formed when no shear is applied to the cement paste. In this resting period, the positive charged ends attach themselves on a negative charged axis, shaping the card-house network [34]. The particle direction will change when shear is applied and compensate the structural connection between particles, improving the structural connection of cement paste and increasing the energy needed for break down. Increases of yield stress and viscosity follow due to this effect [25].

\section{Scope of research}

The objective of this research is to evaluate the effects of different dosages of nanoclay, fly ash and superplasticiser on the fresh and rheological properties and hardening behaviour of cement mortars. Several cement mortars were produced and tested using a statistical modelling approach. The results of the experimental work were analysed and the established models identify and quantify the parameters and two-way interactions that have 
a severe effect on the fresh and hardening properties of cement mortars. The equations obtained can be used to assess the potential influence of adjusting the dosage contents. Dosages can be adjusted to ensure the stability of mortar proportions which include SP, nCL and FA. These models can ease the protocol to optimize mortar with a given set of performance criteria required to ensure successful development of mortar. The proposed models can simplify the test protocol required to optimize a given mix by reducing the number of trial batches needed to achieve optimum balance among various mix variables. This can prove useful even when a set of materials different than that employed for establishing the models is used.

\section{Experimental program}

\subsection{Factor and levels considered}

The considered factors in this research consisted of: Nano-clay with dosages (expressed as mass percentage relative to the mass of cement) varied between 0.5 and $2.5 \%$; superplasticiser dosages (expressed as mass percentage relative to binder, or $0.02 \%$ to $0.08 \%$ by volume of binder) varied between 0.6 and $3 \%$ and fly ash (expressed as mass percentage relative to cement) varied between 5 and 20\%. Table 1 presents a summary of the different values used for each of the factors.

\subsection{Materials used}

The cement used was Portland cement type CEM I $52.5 \mathrm{~N}$, conforming to BS EN 197-1:2000 [35]. Fly ash (FA) in accordance with the BS EN 450-1:2005 is used as cement replacement [36]. Chemical properties of cement and fly ash can be found in Table 2 . Purified palygorskite nano-clay (PPNC) is used as a mineral viscosity modifying admixture (VMA) to control stability and flow of the fresh state. The Acti-Gel 208® used is a highly purified magnesium aluminium silicate that is self-dispersing. Table 3 summarizes the physical properties of the cement, fly ash and nano-clay used. A polycarboxylate-based superplasticiser is used to improve workability in fresh state. Sand was used with a maximum particle size of $1.18 \mathrm{~mm}$, absorption coefficient of $0.3 \%$ and specific gravity of $2.6 \mathrm{mg} / \mathrm{m}^{3}$.

\subsection{Experimental program}

The experimental technique of analysis used in this study was a $2^{\mathrm{k}}$ factorial experimental design to evaluate the influence of two different levels (maximum and 
minimum) for each variable on the relevant mortar properties. Three key parameters that have significant influence on mix characteristics of mortar were selected to use to formulate the statistical models to evaluate relevant properties $(k=3$, therefore the total mixtures for the factorial was $2^{3}=8$ ). The experimental levels of the variables (maximum and minimum) dosages of nCL and SP and the percentage of FA are defined and given in Table 4.

The statistical models are valid for mixtures made with ranges of $\mathrm{nCL}$ of $0.5 \%$ to $2.5 \%$, by mass of binder, $0.6 \%$ to $3.0 \%$ SP dosage, by mass of binder, and fly ash ranged from $5 \%$ to $20 \%$, by mass of cement. The responses modelled were mini-slump, Marsh cone, plate cohesion, heat of hydration, induced bleeding, static yield stress, dynamic yield stress and plastic viscosity, and compressive strengths at $1 \mathrm{~d}, 3 \mathrm{~d}, 7 \mathrm{~d}$ and $28 \mathrm{~d}$.

Eleven mortars were considered during the experiment. The mix proportions of all mortars are listed in Table 4 with percentage factors. The first eight mixtures consist of all possible combinations of the minimum and maximum values of the three factors considered. Mixtures from 9 to 11 are centre points with the same properties that are the average values of the three factors. The percentage of sand was kept constant at $30 \%$ of the total volume for all mixtures.

\subsection{Testing procedure}

The water/binder ratio (W/B) was kept constant at 0.40 for every mortar. Water temperature was kept at $16 \pm 0.5{ }^{\circ} \mathrm{C}$. The mixtures were prepared during 7 minutes in a planar-action high-shear mixer with maximum capacity of $4.5 \mathrm{~L}$. Two batches of every mortar were prepared in the same manner, the first batch consisted of a volume of $1.6 \mathrm{~L}$ and the second of $1.1 \mathrm{~L}$.

Timing and sequence of all operations were the same for all mixtures. First, water, $\mathrm{nCL}$ and SP were poured in the mixer for $1 \mathrm{~min}$ at low speed (140 rpm). Cement, FA and sand were added in the mixer and mixed for $2 \mathrm{~min}$ at low speed. After, the mixer was stopped to remove lumps and to blend any solids on the surface of the mixer. This procedure takes under a minute. The mortar is then mixed for $2 \mathrm{~min}$ on high speed (285 rpm) and for 1 min at low speed (140 rpm).

To perform all the tests in a reasonable time frame, it was decided to produce two batches of the same mixture. On the first batch $(1.6 \mathrm{~L})$ following tests were carried out: the mini-slump, Marsh cone, Lombardi plate and mud balance. Fluidity was tested with the mini-slump flow test ( 8 min after starting mixing). The test was carried out with a truncated 
cone on a PVC plate to measure the spread of mortar. The cone has a bottom diameter of 38 $\mathrm{mm}$, an upper diameter of $19 \mathrm{~mm}$ and height of $57 \mathrm{~mm}$. The spread of the mortar was measured in two perpendicular directions. The value of the spread used further in the research is the average of the two perpendicular measurements. The results of the minislump test give an identification of the yield stress; the lower the average spread, the higher the yield stress is expected $[37,38]$. The Marsh cone test was carried out after $(9 \pm 1 \mathrm{~min})$. The time was measured for the flow through the flow-cone at $500 \mathrm{ml}, 700 \mathrm{ml}$ and $1 \mathrm{~L}$. Lombardi plate cohesion meter was used to measure cohesion $(11 \pm 1 \mathrm{~min})$. The dry thin galvanized steel plate $(100 \times 100 \times 1 \mathrm{~mm})$ was dipped into the mortar and when dripping stopped, placed on a stand on a scale. The weight of the mortar attached to the plate was measured. The thickness of the mixture that adheres to the plate is a dimension for the adhesion, which can be calculated if the density of the mixture is known. The mud balance $(13 \pm 1 \mathrm{~min})$ was used to determine the fresh density of each mortar mixture.

The second batch $(1.1 \mathrm{~L})$ was used for the induced bleeding test and rheological measurements using a computer-controlled vane viscometer. A computer-controlled vane viscometer (Haake VT550 viscometer) was utilized to test the rheology of the mortars. A direct measurement of the yield stress is performed by stress growth $(8-15 \mathrm{~min})$. The method consists of shearing the material at a low and constant rate. The shear stress is quantified and plotted in function of the time. The maximum in the shear stress-time graph determines the yield stress. Around $750 \mathrm{ml}$ or the mortar mixture was placed in a plastic cup in which the vane was inserted. A constant shear rate $\left(0.02 \mathrm{~s}^{-1}\right)$ was applied for $180 \mathrm{~s}$ after a resting period of $60 \mathrm{~s}$. A pressure filter $(9-40 \mathrm{~min})$ was used to measure the resistance of the fresh mortar against induced bleeding. Approximately $200 \mathrm{ml}$ of fresh mortar was placed in the cell with filter paper and closed with the lid by a T-screw in the frame. Under the outlet of the base cap, the graduated cylinder was placed to measure the water loss. Compressed air up to $0.55 \mathrm{MPa}$ was pressured in the cell. The water in the graduated cylinder was measured at $15 \mathrm{~s}, 30 \mathrm{~s}$, and every minute until $10 \mathrm{~min}$ and then every $5 \mathrm{~min}$ to $30 \mathrm{~min}$. After the stress-growth method the test sample is remixed by hand and an indirect measurement is performed with the vane viscometer to obtain the flow curve, dynamic yield stress $\tau_{0}$ and plastic viscosity $\mu$. The step by step method (16-25 min) is used by 10 different steps with constant shear rate. The shear rate is increased and decreased from an initial value of $0.188 \mathrm{~s}^{-1}$ to $41.8 \mathrm{~s}^{-1}$. 

days using a Denison Mayer servo-hydraulic $2000 \mathrm{kN}$ compression machine that applied the load at constant rate of $55 \mathrm{kN} / \mathrm{min}$. The cubes were placed into a water basin at $20 \pm 1{ }^{\circ} \mathrm{C}$ till their testing age. The average compressive strength of three cubes was used further in the research. Heat of hydration was performed on paste samples of each mixture by isothermal calorimetry with an eight-channel heat conduction calorimeter at $22^{\circ} \mathrm{C}$.

\section{Results and Discussion}

The results of the experimental work characterize the behaviour of the mortars with different dosages levels of nCL, FA and SP. Table 5 and 6 summarise all results of the experimental work performed. The results were used to construct the regression models.

To test the significance of the regression models, analysis of variance (ANOVA) was used. To determine non-significant (NS) variables and second order interactions and eliminate them, T-test was used. Multilinear regression analysis based on a normal distribution assumption was used to identify the model coefficients. The error was assumed to be random and normally distributed. The significance of each variable for a given response is evaluated using t-test values based on Student's distribution [39]. Probabilities of less than 0.10 are often considered as strong evidence that the parameter is not zero, i.e. that the proposed parameter has a significant influence on the measured response. Isoresponse curves for the regression models expressed by the equations were created by using response surface methodology (RSM).

Table 7 shows the average measured responses of the three replicate mortars, the coefficients of variation (COV), as well as the estimated errors with a $90 \%$ confidence limit for each of the measured properties. The estimated error levels for mini-slump, flow time, Marsh cone, plate cohesion meter, static yield stress, dynamic yield stress, plastic viscosity, induced bleeding at 10 min, peak of hydration qmax, time of qmax $\mathrm{t}\left(\mathrm{q}_{\max }\right)$, heat of hydration at $1 \mathrm{~d}$ and $3 \mathrm{~d}$, and compressive strengths at $1,3,7,28$ days were $\pm 5.5 \mathrm{~mm}, \pm 2.5 \mathrm{~s}$ $\pm 0.04 \mathrm{~mm}, \pm 6.0 \mathrm{~Pa}, \pm 3.8 \mathrm{~Pa}, \pm 0.32 \mathrm{~Pa} . \mathrm{s}, \pm 2.7 \mathrm{~mL}, \pm 0.003 \mathrm{~W} / \mathrm{kg}, \pm 0.006 \mathrm{day}, \pm 0.002 \mathrm{~W} / \mathrm{kg}$, $\pm 0.003 \mathrm{~W} / \mathrm{kg}, \pm 2.7 \mathrm{MPa}, \pm 0.7 \mathrm{MPa}, \pm 0.4 \mathrm{MPa}, \pm 2.5 \mathrm{MPa}$, respectively (Table 7). 


\subsection{Mini-slump}

The mini-slump is mainly influenced by the dosages of nCL, SP and FA and by some interaction effects between SP and FA. Nano-clay and SP dosage are the parameters affecting the mini-slump the most, as shown in Eq. (1) $\left(\mathrm{R}^{2}=0.99\right)$ :

$$
\text { Mini-slump }[\mathrm{mm}]=114.4-44.0 \mathrm{nCL}+32.1 \mathrm{SP}-5.5 \mathrm{FA}-5.0 \mathrm{SP} \cdot \mathrm{FA}
$$

Fig. 1 shows the effect of nCL with respectively FA and SP fixed. Both graphs illustrate a decrease in mini-slump with an increasing dosage of nCL between 0.5 and $2.5 \%$. The content of nCL is the most dominant factor for reducing the mini-slump because of its high-water adsorption and thixotropic behaviour Error! Reference source not found. followed by SP (-44 and 32.1 in Eq. 1). Acti-gel is known for increasing the stiffness of fresh concrete [21]. The mixtures with the highest nCL content $(2.5 \%)$ were clearly stiffer and even resulted in mixtures 2 and 6 being not flowable.

\subsection{Marsh cone flow time}

The regression model for the Marsh cone is influenced in order of significance by nCL, FA and SP as presented in Eq. (2) with $\mathrm{R}^{2}=0.98$. The flow time for $700 \mathrm{ml}$ of mortar flowing through the Marsh cone was investigated. Flowability is significantly influenced by nCL dosage. The higher the nCL dosage, the longer it takes for the mortar to flow through the funnel as the mix became to viscous to flow.

1/Marsh cone $\left[\mathrm{s}^{-1}\right]=0.028-0.017 \mathrm{nCL}+0.008 \mathrm{SP}-0.004 \mathrm{FA}-0.003 \mathrm{SP} F A$

Fig. 2 shows that variations in the nCL content become more important when the FA content is increased or the SP content is reduced. Fixed SP at $1.8 \%$ and FA at $12.5 \%$, increasing nCL content from $0.5 \%$ to $2.0 \%$ led to an increase of flow time from $22 \mathrm{~s}$ to $50 \mathrm{~s}$. For example, when SP was fixed at $1.2 \%$ and FA at $12.5 \%$, the increases of nCL content from $0.5 \%$ to $2.0 \%$ led to an increase of flow time from $25 \mathrm{~s}$ to $63 \mathrm{~s}$. The same trend on increase of flow time can be noticed for SP but in this case with reducing SP dosage.

\subsection{Plate cohesion}

Dosages of nCL, FA and their interaction were found significant in the analysis of the Lombardi plate test results as mentioned in Eq. (3) with $\mathrm{R}^{2}=0.96$. The thickness of the layer on the plate is primarily affected by the main effects of nCL and FA. 
Plate cohesion $[\mathrm{mm}]=0.92+0.49 \mathrm{nCL}-0.18 \mathrm{SP}+0.15 \mathrm{FA}-0.12 \mathrm{nCL} \cdot \mathrm{SP}$

$$
+0.13 \mathrm{SP} \cdot \mathrm{FA}
$$

Fig. 3 shows the contour plots for fixed SP and variable nCL versus FA. It illustrates that at fixed SP at $1.8 \%$ and FA at $12.5 \%$, the increases of nCL content from 1.0 to $2.5 \%$ led to an increase of plate cohesion from $0.70 \mathrm{~mm}$ to $1.28 \mathrm{~mm}$. When SP was fixed at $2 \%$ and $\mathrm{nCL}$ at $2 \%$, the increases in FA content from 5 to $20 \%$ led to an increase of plate cohesion from $1.1 \mathrm{~mm}$ to $1.4 \mathrm{~mm}$ indicating that both FA and $\mathrm{nCL}$ and their interaction improve the cohesiveness of mortars. Thus, increasing the ultrafine nCL particles content improved the cohesion of the mortar and reduced segregation tendencies.

\subsection{Rheological parameters}

The flow curve was fitted by using the Modified Bingham model. Eqs. (4), (5) (6) show the static yield stress $\left(\mathrm{R}^{2}=0.95\right)$, dynamic yields stress $\left(\mathrm{R}^{2}=0.99\right)$ and plastic viscosity $\left(\mathrm{R}^{2}=0.97\right)$, respectively. Eq. (4) shows that the increase of $\mathrm{nCL}$ content led to an increase in static stress (Fig. 4), dynamic yield stress (Fig. 5) and plastic viscosity (Fig. 6). The trend for yield stress regarding nCL and SP is found to be consistent with the model for the mini-slump test. Increasing nano-clay dosages has 3.4 times more effect on increasing the static yield stress than SP has on decreasing it. However, the increase of SP led to a reduction of yield stress and a slight reduction of plastic viscosity (Figs. 5 and 6). A thicker polymer layer is formed by increasing the SP dosage with a weaker attraction between particles consequently. Therefore, a smaller force is needed to disperse the particles. The increase in yield stress is due to the card-house like microstructure formed by the very small particles of nCL, that is more difficult to break down. The replacement of cement by fly ash affects significantly the yield stress and plastic viscosity. Increasing FA led to a reduction of yield stress and slight increase in plastic viscosity due to the balling effect of spherical particles of FA.

1/Static yield value $\left[\mathrm{Pa}^{-1}\right]=0.044-0.034 \mathrm{nCL}+0.010 \mathrm{SP}-0.029 \mathrm{FA}+0.026 \mathrm{nCL} \cdot \mathrm{FA}$

Yield value $[\mathrm{Pa}]=19.1+16.7 \mathrm{nCL}-31.9 \mathrm{SP}-16.4 \mathrm{FA}+13.4 \mathrm{nCL}$ FA

1/Plastic viscosity $\left[\mathrm{Pa} \cdot \mathrm{s}^{-1}\right]=0.39-0.15 \mathrm{nCL}+0.14 \mathrm{SP}-0.056 \mathrm{FA}$ 
In general conclusion on fresh and rheological properties, the results of effect nanoclay on these properties concord on what have been reported in the literature [23, 32].

\section{$4.5 \quad$ Induced bleeding}

For induced bleeding, the following relationship was obtained at $10 \mathrm{~min}$ having the best $\mathrm{R}^{2}=0.94$ (Eq. 7). The proportion of SP exhibits the most effect as a primary variable on the induced bleeding at $10 \mathrm{~min}$ when the most induced bleeding happened (Eq. (7) followed by nCL. However, the addition of FA led to slight increase of induced bleeding and also the interaction between CL and SP had the most significant effect on induced bleeding (5.1 vs. $-3.3,-1.3$ and 0.75$)$.

Induced bleeding at $10 \mathrm{~min}[\mathrm{~mL}]=10.9-1.3 \mathrm{nCL}-3.3 \mathrm{SP}+0.75 \mathrm{FA}$

$$
+5.1 \mathrm{nCL} \cdot \mathrm{SP}
$$

The isoresponse curve in Fig. 7 shows that a critical value is reached around $1.8 \%$ SP and $2 \%$ nCL and $12.5 \%$ of fly ash. Increasing the dosage of nCL between 0.5 and $2.5 \%$ with SP content below $1.8 \%$ and fixed FA at $12.5 \%$, caused a decrease in induced bleeding at 10 min between 20 and $10 \mathrm{~mL}$. When SP content is higher than $2 \%$ and FA fixed, the bleeding reduced with nCL content ranging from 0.5 to $2 \%$. The effect is due to better dispersion and packing of cement particles related to higher SP content which led to more sedimentation of cement particles at the bottom and blocking the filer and therefore less bleeding. For any given nCL percentage and fixed SP content, the increase of FA led to an increase in the bleeding (Fig. 7).

\subsection{Heat of hydration}

Eq. (7) and (8) show the retarding and decreasing effect of increasing FA and SP content on the peak of hydration $\mathrm{q}_{\max }$ and the time corresponding of $\mathrm{t}\left(\mathrm{q}_{\max }\right)$ with $\mathrm{R}^{2}$ of 0.99 and 0.99 , respectively. The nCL content shows slight significant effect on peak of hydration and an interaction between nCL and SP (+0.001 and -0.34). However, SP and FA had high significance on peak of hydration. Eq. (9) and (10) show that increasing FA content decreased significantly the heat released at day 1 and 3 day $(-0.23$ and -0.017$)$, while increasing SP content increased the heat release as it improves the reaction of cement particles (better dispersion). The coefficient of determination of heat at $1 \mathrm{~d}$ and $3 \mathrm{~d}$ were 
0.99 and 0.98 , respectively. However, the increase in dosage of nCL reduced slightly the heat of hydration at $1 \mathrm{~d}$ and $3 \mathrm{~d}(-0.09$ and -0.005$)$. Figs. 8 and 9 present the isoresponse of heat of hydration at $1 \mathrm{~d}$ and 3 days, respectively. For fixed SP at $1.8 \%$ and any given nCL content, the increase of FA led to a reduction of heat of hydration at $1 \mathrm{~d}$ and $3 \mathrm{~d}$ (Figs. 8 and 9). Conversely, the increase of SP for a fixed FA at $12.5 \%$ and any give dosage of nCL induced a slight increase in heat of hydration at $1 \mathrm{~d}$ and 3 days.

Peak of hydration $\mathrm{q}_{\max }[\mathrm{W} / \mathrm{kg}]=2.08-0.21 \mathrm{SP}-0.19 \mathrm{FA}+0.001 \mathrm{nCL}$

$$
-0.034 \mathrm{nCL} \cdot \mathrm{SP}
$$

Peak of hydration $\mathrm{t}\left(\mathrm{q}_{\max }\right)[$ day $]=0.92+0.24 \mathrm{SP}+0.057 \mathrm{FA}+0.026 \mathrm{SP} \cdot \mathrm{FA}$

$1-\mathrm{d}$ heat $[\mathrm{W} / \mathrm{kg}]=1.46-0.23 \mathrm{FA}+0.19 \mathrm{SP}-0.090 \mathrm{nCL}+0.091 \mathrm{nCL} \cdot \mathrm{SP}-0.25 \mathrm{SP} \cdot \mathrm{FA}(9)$

$3-\mathrm{d}$ heat $[\mathrm{W} / \mathrm{kg}]=0.25-0.017 \mathrm{FA}+0.017 \mathrm{SP}-0.005 \mathrm{nCL}+0.005 \mathrm{SP} \cdot \mathrm{FA}$

\subsection{Compressive strength}

Eqs. (12), (13), (14) and (15) present the relations between the compressive strength and nCL, SP and FA content at age 1, 3, 7 and 28 days with very good coefficients of determination $\mathrm{R}^{2}=0.94,0.97,0.98,0.95$, respectively). The 3 parameters $\mathrm{nCL}, \mathrm{SP}$ and FA had a significant effect on the compressive strengths. The increase of nCL content had a different effect on the compressive strength depending on the age. A positive effect was noticed at day 1 but the effect turns negative from day 3 till 28 days, becoming more significant with age. The compressive strength increased at 3, 7 and 28 days with increased dosages of SP, depending on the nCL dosage. The same positive effect was noticed in the 1day and 3-day heat equations (9) and (10). However, as expected FA led to a reduction of compressive strength at all ages.

$\mathrm{f}_{\mathrm{c} 1 \mathrm{~d}^{\prime}}[\mathrm{MPa}]=16.8+1.8 \mathrm{nCL}-6.0 \mathrm{SP}-1.6 \mathrm{FA}+1.6 \mathrm{nCL} \cdot \mathrm{SP}$

$\mathrm{f}_{\mathrm{c} 3 \mathrm{~d}^{\prime}}[\mathrm{MPa}]=44.3-3.4 \mathrm{nCL}-1.5 \mathrm{FA}+0.8 \mathrm{SP}+2.8 \mathrm{nCL} \cdot \mathrm{SP}-0.9 \mathrm{nCL} \cdot \mathrm{FA}$

$\mathrm{f}_{\mathrm{c} 7 \mathrm{~d}^{\prime}}[\mathrm{MPa}]=57.2-3.8 \mathrm{nCL}+5.0 \mathrm{SP}-2.4 \mathrm{FA}+2.5 \mathrm{nCL} \cdot \mathrm{SP}-2.4 \mathrm{nCL} \cdot \mathrm{FA}$

$\mathrm{f}_{\mathrm{c} 28 \mathrm{~d}}[\mathrm{MPa}]=72.4-5.1 \mathrm{nCL}+4.3 \mathrm{SP}-2.2 \mathrm{FA}+2.5 \mathrm{nCL} \cdot \mathrm{SP}-1.3 \mathrm{nCL} \cdot \mathrm{FA}$

At one day, the increase of SP dosage showed a negative effect on the compressive strength. The interaction between $\mathrm{nCL}$ and $\mathrm{SP}$ with positive effect on the compressive 
strength was found to be significant at all ages, especially at the age of 3 days. The isoresponse curve for the compressive strength at 3 days Fig. 10(b) illustrates that for a nCL dosage less than $1.2 \%$, increasing SP dosage has a negative effect on the compressive strength, but for a higher nCL dosage (between 1.2 and $2.5 \%$ ) had a positive effect. The compressive strength results for fixed SP and FA show that mortars with higher nCL content developed a higher compressive strength at day 1 compared to the same mortar with low nCL content. The compressive strength at 3, 7 and 28 days was higher for the mortars with low nCL content.

As expected FA content affected the compressive strength at all ages in the same way; increased FA dosages reduced the compressive strength. This effect coincides with the negative effect of FA dosage on the hydration peak, 1-day heat and 3-day heat.

Fig. 10 shows the isoresponse curves for nCL versus SP for 1, 3, 7 and 28 days with FA fixed at $12.5 \%$. At $1 \mathrm{~d}$, an increase of $2 \mathrm{MPa}$ is noticed for increasing nCL content with SP at $1.8 \%$ and FA at $12.5 \%$. The increase became smaller with lower SP and bigger with higher SP due to their interactions. At 3 days, a reduction in compressive strength is noticed with increasing nCL content between 0.5 and $1.25 \%$ and increasing SP content between 0.6 and $3 \%$. An increase is observed when $\mathrm{nCL}$ content is above $1.25 \%$ with increasing SP content. At 7 days, nCL content decreased the compressive strength and SP increased it. A larger reduction is noticed at fixed low SP content (-10 MPa) with increasing nCL content (-3 MPa). The same effect at 7 days is noticed at 28 days.

Fig. 11 shows the isoresponse curves for nCL versus FA for 1, 3, 7 and 28 days with SP fixed at $1.8 \%$. Similar effects for $\mathrm{nCL}$ can be found previously, FA reduced the compressive strength. Interactions between $\mathrm{nCL}$ and FA are seen to be similar to FA at 7 days (-2.4). nCL dosage led to a reduction of $20 \mathrm{MPa}$ (66 to $56 \mathrm{MPa}$ ) when FA content is increased. At 28 days, for fixed low dosages of nCL led a reduction of approximately 2 MPa (80 to $78 \mathrm{MPa}$ ), but at fixed high dosage of $\mathrm{nCL}$, the reduction was about 7MPa when FA content increased.

\subsection{XRD}

An XRD was performed on two pastes samples of mixture composition $1(0.50 \%$ nCL, $0.60 \%$ SP, 5\%FA) and $2(2.50 \% \mathrm{nCL}, 0.60 \% \mathrm{SP}, 5 \% \mathrm{FA})$ at age 1 day and 7 days in order to attempt to explain the strength loss at later age of the mortars with higher nCL 
content. The W/C ratio of paste 1 was 0.42 and paste 2 was 0.43 . The pastes were hand mixed and contained no sand. The paste cubes were formed and crushed at 1 day and 7 days before the XRD was performed. Results of XRD are presented in Fig. 12.

The compressive strength of the paste cubes did not show the same trend as the mortars (Table 7). It can be seen that the compressive strengths for the pastes are very similar for the two different pastes at both ages, whilst the compressive strength for the mortar 2 is higher at 1 day and lower at 7 days in comparison with mortar 1.

The percentage of the mineral components for the two pastes at 1 day and 7 days are listed in Table 8. The percentages relate to what was noticed in the compressive strength. The XRD results for the same age are very similar and translated into similar compressive strength. Looking at day 1 , Table 8 shows a slight reduction in $\mathrm{C}_{3} \mathrm{~S}$ and a slight increase in $\mathrm{CH}$ and Amorphous (containing C-S-H) for paste 2. This translates into the small increase in compressive strength for paste 2 at 1 day. However, the difference in compressive strength for the mortars at $1 \mathrm{~d}$ is higher, so the differences in $\mathrm{C}_{3} \mathrm{~S}, \mathrm{CH}$ and Amorphous were expected higher. The same goes for the pastes at 7 days, the percentages are very similar and result in a similar compressive strength. The XRD demonstrates that there is no effect of nano-clay when paste is used. The compressive strength for the mortars would indicate a significant decrease in $\mathrm{C}_{3} \mathrm{~S}$ and increase in $\mathrm{CH}$ and Amorphous for mortar 1 in comparison with mortar 2 results in a higher compressive strength at 7 days.

The results from the XRD coincide of what could be expected from the heat of hydration and results in a similar compressive strength for both mixtures, but did not indicate the varying compressive strength of the mortars. The decreasing compressive strength of the mortars could possibly be caused by increased air entrained in the mortar with increasing nano-clay content. This could be investigated by determining the percentage of air in the mortars and using scanning electron microscope (SEM) with digital image processing at different ages. This explanation was also reported by Garg and Wang Error! Reference source not found. where a decrease in strength with increasing amounts of nCL was also noticed. It was assigned to the high-water adsorption property of Acti-gel where higher air content was found with increasing Acti-Gel percentage. The sample cubes in that research showed large air pockets and had a honeycombed surface. The increase on air content was explained since the lubricated water was absorbed by the fine particles of the nano-clay, which leaves the voids filled with air. An increased viscosity can be noticed with 
increasing amount of nano-clay due to floc formation of nCL. This increase in viscosity was also noticed in this study in Eq. (6). Mortars with increasing Acti-gel percentage are found to be stiffer and less flowable, as shown by Eq. (2). The voids system should show higher air content and reduced free water with higher nCL dosage.

\subsection{Desirability functions for optimisation}

The numerical optimization for the performance characteristics of mortar was carried out for two examples having different criteria. Optimisation analysis has been performed for a combination of factor levels considered in this study that simultaneously satisfy the requirements of each response selected in the optimisation. The simultaneous optimisation for each response has a low and high value assigned to each goal. From the numerical optimisation, the goal for responses is one of five cases: none, maximum, minimum, target, or in a specified range. Each goal is assigned a weight between one (least important) and five (most important). Factors nCL, SP and FA are included in the optimisation, at their design range which is: as a maximum or minimum of a target goal. The goals are then combined into an overall desirability function, which reflects the desirability ranges for each response selected in the numerical optimisation. The values of desirability function are ranged from zero to one for any given response. Goal desired begins at a random starting point and proceeds up the steepest slope to a maximum value. In same case, there may be two or more maximum values because of the curvature of the response surfaces and their combination with the desirability function. The value equals to one within the experimental domain represents the ideal case whereas zero may indicate that one or more responses fall outside the desirable limits. To illustrate this concept, Table 9 summarises the goals and weights for the measured responses selected in this study (mini-slump, Marsh cone, cohesion plate, yield stress, plastic viscosity, induced bleeding heat of hydration, and compressive strength at $1 \mathrm{~d}, 3 \mathrm{~d}, 7 \mathrm{~d}$ and $28 \mathrm{~d}$.

Two examples are illustrated in this paper; the solutions of the desirability function are summarised in Table 9 and contours of these desirability functions are plotted in Figures 13 and 14. In Example 1, the mix parameters (nCL, SP, FA) were kept within the experimental ranges. In Example 2, both nCL and SP were minimised and FA was kept within the range. At dosage of nCL of $1.36 \%$, the response surface in Figure 13 indicated for example 1 that the desirability function increased with an increase in SP and a reduction of FA. When FA 
is fixed at 5\% and SP at 3\% were in the range to maximize the fluidity and strength while minimizing Marsh cone time, yield stress, plastic viscosity, and induced bleeding (Table 9), the desirability function was 0.649 (Figure 13). The solution of the desirability function has been changed in case of example 2 when different goals or weights have been selected for the numerical optimisation by minimising $\mathrm{nCL}$ and SP and keeping the goals and weight for all criteria similar to those in Example 1. In this case of example 2, the optimum solution for the desirability function became 0.633 and was achieved with $0.5 \%$ nCL and $1.8 \%$ SP with FA of $8.9 \%$ (Figure 14).

\section{Conclusions}

This paper investigated the effects of dosages of nano-clay (nCL), fly ash (FA) and superplasticiser (SP) on the fresh and rheological properties, induced bleeding at $10 \mathrm{~min}$, heat of hydration at 1 and 3 days and compressive strength of cement-based mortars at $1 \mathrm{~d}, 3$ $\mathrm{d}, 7 \mathrm{~d}$, and $28 \mathrm{~d}$. Based on the results from this investigation, the following conclusions can be made:

- The increase of nano-clay content caused a reduction in mini-slump, induced bleeding, heat production at 1 and 3 days, and compressive strength at age 3, 7 and 28 days. An increase in the flow time, plate cohesion, static and dynamic yield stresses, plastic viscosity, peak of hydration and compressive strength at age 1 day were noticed with increasing nano-clay dosages. The fresh properties were significantly influenced by the high-water adsorption of nano-clay. The rheological parameters were influenced by the formed card-house like microstructure which increased the resistance against break down. Nano-clay was found the most significant factor in reducing mini-slump and compressive strength at $3 \mathrm{~d}$ and $28 \mathrm{~d}$, and increasing flow time, plate cohesion, static yield stress and plastic viscosity.

- The increase of dosage of SP led to an increase in mini-slump, heat hydration at $1 \mathrm{~d}$ and $3 \mathrm{~d}$ and the compressive strength at age 3, 7 and 28 days. A reduction in flow time, plate cohesion, static and dynamic yield values, plastic viscosity, induced bleeding and compressive strength at 1 day was noticed with increasing SP. These effects came from the lubricating effect of SP caused by better repulsion between cement particles that react with superplasticiser on their surface. SP was found the most significant factor in reducing the induced bleeding and compressive strength at $1 \mathrm{~d}$ and increasing heat and compressive strength at $3 \mathrm{~d}$. Additionally, the increase in 
SP also had the most significant effect on reducing and decelerating the peak of hydration.

- The addition of fly ash (FA) content for a fixed nCL and SP led to an increase in flow time, plate cohesion, static yield stress, plastic viscosity and induced bleeding and a reduction in mini-slump, dynamic yield value, heat of hydration and compressive strength at age 1, 3, 7 and 28 days. Higher fly ash percentage caused the peak of hydration to prolong and reduce. Increasing FA was found the most significant factor in reducing heat at $1 \mathrm{~d}$ and $3 \mathrm{~d}$.

- The effect of interaction between nCL and SP was found to be the most significant factor on the induced bleeding. An optimum was found at 2\% SP and 1.9\% nCL. Increasing the dosage of nCL between 0.5 and $2.2 \%$ with SP content below $1.9 \%$ and fixed FA at $12.5 \%$, led to a reduction in inducing bleeding. When SP content is higher than 2\% and FA fixed, the induced bleeding reduced with lower percentage of nCL. The effect is due to better dispersion and packing of cement particles related to higher SP content.

- The XRD results on two paste mixtures showed no effect of nano-clay addition. The reduction of compressive strength of the mortars could possibly be caused by an increase in air entrained in the mortar with an increase in nCL content. The increase on air content could be due to absorption of the lubricated water by the fine particles of the nano-clay which leaves the voids filled with air. An increased viscosity can be noticed with increasing amount of nano-clay due to floc formation of nCL. Generally, the mortars with higher nCL percentage are found to be stiffer and less flowable.

- The numerical optimisation of both examples showed that the response of the desirability function obtained with different variables based on the specified goals target can be changed as the best solution of the desirability function.

\section{ACKNOWLEDGEMENTS}

The authors would like to acknowledge the support of the technical staff and the facilities provided by the School of Natural and Built Environment at Queen's University of Belfast. We thank Faber \& Vanderende Chemicals - Minerals to provide us Acti-Gel 208. 


\section{References}

498

499

500

501

502

503

504

505

506

507

508

509

510

511

512

513

514

515

516

517

518

519

520

521

522

523

524

525

526

527

528

529

[1] Sebök T, Šimoník J, Kulísek K. The compressive strength of samples containing fly ash with high content of calcium sulfate and calcium oxide. Cement and Concrete Research 2001;31:1101-7. doi:10.1016/S0008-8846(01)00506-3.

[2] Biricik H, Sarier N. Comparative study of the characteristics of nano silica - , silica fume - and fly ash - incorporated cement mortars. Mat Res 2014;17:570-82. doi:10.1590/S1516-14392014005000054.

[3] García-Taengua E., Sonebi M., Hossain KMA., Lachemi M., Khatib J. Effects of the addition of nanosilica on the rheology, hydration and development of the compressive strength of cement mortars. Composites Part B Journal 2015; 81:120-129.

[4] Kawashima S., Hou P., Corr D.J., Shah S.P. Modification of cement-based materials with nanoparticles. Cement and Concrete Composites 2013; 36: 8-15.

[5] Sobolev K, Flores I, Hermosillo R. Nanomaterials and nanotechnology for highperformance cement composites. ACI Special Publication 2008;254:93-120.

[6] Zapata LE, Portela G, Suárez OM, Carrasquillo O. Rheological performance and compressive strength of superplasticized cementitious mixtures with micro/nano- $\mathrm{SiO}_{2}$ additions. Construction and Building Materials 2013;41:708-16. doi:10.1016/j.conbuildmat.2012.12.025.

[7] Konsta-Gdoutos MS. Nanomaterials in self-consolidating concrete: a state-of-the-art review. Journal of Sustainable Cement-Based Materials 2014:1-15. doi:10.1080/21650373.2014.909751.

[8] Sonebi M., Garcia E., Hossain K.A., Khatib J., Lachemi M. Effect of nanosilica on the fresh properties and shrinkage of mortars with fly ash and superplasticizer. Construction and Building materials 2015;84, 269-276.

[9] Sonebi M, Bassuoni MT., Kwasny J, Amanuddin AK. Effect of Nanosilica on Rheology, Fresh Properties, and Strength of Cement-Based Grouts. Journal Mat. in Civ Eng. 2014:04014145. doi:10.1061/(ASCE)MT.1943-5533.0001080.

[10] Abd El Aleem S, Heikal M, Morsi WM. Hydration characteristic, thermal expansion and microstructure of cement containing nano-silica. Construction and Building Materials 2014;59:151-60. doi:10.1016/j.conbuildmat.2014.02.039.

[11] Sanchez F, Sobolev K. Nanotechnology in concrete - A review. Construction and Building Materials 2010;24:2060-71. doi:10.1016/j.conbuildmat.2010.03.014. 
[12]Björnström J, Martinelli A, Matic A, Börjesson L, Panas I. Accelerating effects of colloidal nano-silica for beneficial calcium-silicate-hydrate formation in cement. Chemical Physics Letters 2004;392:242-8. doi:10.1016/j.cplett.2004.05.071.

[13] Singh LP, Karade SR, Bhattacharyya SK. Beneficial role of nanosilica in cement based materials-a review. Construction and Building Materials 2013;47:1069-77. doi:10.1016/j.conbuildmat.2013.05.052.

[14]Berra M, Carassiti F, Mangialardi T, Paolini AE, Sebastiani M. Effects of nanosilica addition on workability and compressive strength of Portland cement pastes. Construction and Building Materials 2012;35:666-75. doi:10.1016/j.conbuildmat.2012.04.132.

[15]Lin DF., Lin KL., Chang WC., Luo HL., Cai MQ. Improvements of nano-SiO 2 on sludge/fly ash mortar. Waste Manage. 2008;28: 1081-1087.

[16]Zyganitidis I., Stefanidou M., Kalfagiannis N., Logothetidis S. Nanomechanical characterization of cement-based pastes enriched with $\mathrm{SiO}_{2}$ nanoparticles. Mater. Sci. Eng. B. 2011;176: 1580-1584.

[17]Maravelaki-Kalaitzaki P., Agioutantis Z., Lionakis E., Stavroulaki M., Perdikatsis V. Physico-chemical and mechanical characterization of hydraulic mortars containing nano-titania for restoration applications. Cem. Concr. Compos. 2013;36: 33-41.

[18]Polat R., Demirboğa R., Khushefati WH. Effects of nano and micro size of $\mathrm{CaO}$ and $\mathrm{MgO}$, nano-clay and expanded perlite aggregate on the autogenous shrinkage of mortar. Constr. Build. Mater. 2015;81: 268-275.

[19]Theodoridou M., Charalambous E., Maravelaki-Kalaitzaki P., Ioannou I. Amelioration of crushed brick-lime composites using nanoadditives. Cem. Concr. Compos. 2016;68: 77-87.

[20]Kong D., Huang S., Corr D., Yang Y., Shah S.P. Whether do nano-particles act as nucleation sites for C-S-H gel growth during cement hydration?. Cem. Concr. Compos. 2018;87: 98-109.

[21]Tregger NA., Pakula ME., Shah, SP. Influence of clays on the rheology of cement pastes. Cement and Concrete Research 2010;40(3): 384-391.

[22]Morsy M., Alsayed SH. and Aqel M. Effect of Nano-clay on Mechanical Properties and Microstructure of Ordinary Portland Cement Mortar, International Journal of Civil \& Environmental Engineering IJCEE-IJENS 10.01 (2010): 23-27.

[23] Kawashima S., Hou P., Corr D.J., Shah SP. Modification of cement-based materials with nanoparticles. Cement and Concrete Composites 2013; 36: 8-15. 
[24][1]Neaman A., Singer A. Rheological properties of aqueous suspensions of palygorskite. Soil Science Society of America Journal 2000;64(1): 427-436.

[25][1]Quanji Z. Thixotropic behavior of cement-based materials: effect of clay and cement types (doctoral dissertation). State University, Iowa, IA, 2010.

[26][1]Garg N., Wang K. Comparing the performance of different commercial clays in fly ash-modified mortars. Journal of Sustainable Cement-Based Materials 2012;1(3): 111125 .

[27][1]De Schutter G. Effect of limestone filler as mineral addition in self-compacting concrete. Proceedings of the 36th Conference on Our World in Concrete \& Structures, Singapore, Eds. C.T. TAM et al., 2011, ISBN 978-981-08-9528-0, abstract p.23-24, paper on CD-ROM, 49-54.

[28]Libya Ahmed, Sbiaa Amirpasha Peyvandib Parviz Soroushiana Anagi M. Balachandrac Konstantin Sobolevd, Evaluation of modified-graphite nanomaterials in concrete nanocomposite based on packing density principles, Construction and building materials 76 (2015): 413-422.

[29] Ye G., Liu X., De Schutter G., Poppe A.-M., Taerwe L. Influence of limestone powder used as filler in SCC on hydration and microstructure of cement pastes. Cement \& Concrete Composites 2007;29: 94-102.

[30]Meng, T ; Hong, YP ; Wei, HD ; Xu, QL, Effect of nano-SiO2 with different particle size on the hydration kinetics of cement, THERMOCHIMICA ACTA, Volume: 675 , Pages: 127-133 , DOI: 10.1016/j.tca.2019.03.013.

[31] Sharma, U ; Ali, D ; Singh, LP., Formation of C-S-H nuclei using silica nanoparticles during early age hydration of cementitious system, EUROPEAN JOURNAL OF ENVIRONMENTAL AND CIVIL ENGINEERING DOI: 10.1080/19648189.2019.1583135.

[32] Shiho Kawashima, Jae Hong Kim, David J. Corr, Surendra P. Shah, Study of the mechanisms underlying the fresh-state response of cementitious materials modified with nanoclays, Construction and Building Materials 36 (2012) 749-757.

[33] Shiho Kawashima, Mohend Chaouche, David J. Corr, Surendra P. Shah, Rate of thixotropic rebuilding of cement pastes modified with highly purified attapulgite clays, Cement and Concrete Research 53 (2013) 112-118.

[34]Qian Y., De Schutter G. Enhancing thixotropy with nanoclay in presence of polycarboxylate ether superplasticizer (PCE). Cement and Concrete Research 2018; 111: 15-22, doi:10.1016/j.cemconres.2018.06.013. 
598 [35] European Committee for Standardization. EN 450-1:2012 Fly ash for concrete - Part 1:

599 Definition, specifications and conformity criteria. 2012. doi:10.3403/03270538.

600 [36] European Committee for Standardization. EN 197-1: 2011 Cement - Part 1:

601 Composition, specifications and conformity criteria for common cements. 2011.

602 [37]Pierre A, Lanos C, Estellé P. Extension of spread-slump formulae for yield stress 603 evaluation. Applied Rheology 2013;23:63849.

604 [38] Roussel N, Coussot P. Fifty-cent rheometer for yield stress measurements: From slump 605 to spreading flow. Journal of Rheology 2005;49:705-718. $606 \quad$ http://dx.doi.org/10.1122/1.1879041.

607 [39]Montgomery D. (2001) "Design and analysis of experiments," John Wiley \& Sons, $608 \quad$ New York.

609

610

611

612

613

614

615 
617 Table 1

618 Factor levels of variables

$$
\text { Coding values }
$$

\begin{tabular}{lccc}
\hline Parameter & \multicolumn{1}{c}{-1} & Central point & +1 \\
\hline Nano-clay (nCL) & $0.5 \% \mathrm{o} / \mathrm{c}$ & $1.5 \% \mathrm{o} / \mathrm{c}$ & $2.5 \% \mathrm{o} / \mathrm{c}$ \\
Superplasticiser (SP) & $0.6 \% \mathrm{o} / \mathrm{b}$ & $1.8 \% \mathrm{o} / \mathrm{b}$ & $3 \% \mathrm{o} / \mathrm{b}$ \\
Fly ash (FA) & $5 \% \mathrm{o} / \mathrm{c}$ & $12.5 \% \mathrm{o} / \mathrm{c}$ & $20 \% \mathrm{o} / \mathrm{c}$ \\
\hline
\end{tabular}

619

\section{Table 2}

621 Chemical compositions of cement and fly ash

\begin{tabular}{rcc}
\hline$[\%]$ & Cement & Fly ash \\
\hline $\mathrm{SiO}_{2}$ & 19.83 & 56 \\
$\mathrm{Al}_{2} \mathrm{O}_{3}$ & 4.8 & 23.3 \\
$\mathrm{Fe}_{2} \mathrm{O}_{3}$ & 3.02 & 4.8 \\
$\mathrm{SO}_{3}$ & 2.48 & -- \\
$\mathrm{MgO}$ & -- & 1.9 \\
$\mathrm{CaO}$ & 63.06 & 4.8 \\
$\mathrm{Na}_{2} \mathrm{O}$ & -- & 0.9 \\
$\mathrm{~K}_{2} \mathrm{O}$ & -- & 1.8 \\
$\mathrm{LO}$ & 3 & 3.5 \\
$\mathrm{SO}_{3}$ & 2.48 & 0.7 \\
\hline
\end{tabular}

622

\section{Table 3}

624 Physical properties of cement, fly ash and nano-clay

\begin{tabular}{lccc}
\hline & Cement & Fly ash & Nano-clay \\
\hline Loss on ignition $[\%]$ & 1.26 & -- & -- \\
Specific gravity & 3.13 & 2.21 & 2.29 \\
$\%$ passing $45 \mu \mathrm{m}$ sieve & 82 & 85 & -- \\
Mean particle size $[\mu \mathrm{m}]$ & 32 & -- & -- \\
Average particle diameter $[\mathrm{nm}]$ & -- & -- & 3.0 \\
Average particle length $[\mu \mathrm{m}]$ & -- & -- & $1.5-2.0$ \\
\hline
\end{tabular}

625 
Table 4

628 Test mortars proportions

\begin{tabular}{lccccc}
\hline & Ref. & W/B & $\begin{array}{c}\text { Nano-clay } \\
{[\%]}\end{array}$ & $\begin{array}{c}\text { SP } \\
{[\%]}\end{array}$ & $\begin{array}{c}\text { FA } \\
{[\%]}\end{array}$ \\
\hline Selected & 1 & 0.40 & 0.50 & 0.60 & 5.0 \\
mixtures & 2 & 0.40 & 2.50 & 0.60 & 5.0 \\
& 3 & 0.40 & 0.50 & 3.00 & 5.0 \\
& 4 & 0.40 & 2.50 & 3.00 & 5.0 \\
& 5 & 0.40 & 0.50 & 0.60 & 20.0 \\
& 6 & 0.40 & 2.50 & 0.60 & 20.0 \\
& 7 & 0.40 & 0.50 & 3.00 & 20.0 \\
Centre & 8 & 0.40 & 2.50 & 3.00 & 20.0 \\
& 9 & 0.40 & 1.50 & 1.80 & 12.5 \\
& 10 & 0.40 & 1.50 & 1.80 & 12.5 \\
& 11 & 0.40 & 1.50 & 1.80 & 12.5 \\
\hline
\end{tabular}

629

630 Table 5

631 Results of experimental work

\begin{tabular}{|c|c|c|c|c|c|c|c|}
\hline \multirow[b]{2}{*}{ Mix } & \multirow[b]{2}{*}{$\begin{array}{c}\text { Mini-slump } \\
{[\mathrm{mm}]}\end{array}$} & \multirow[b]{2}{*}{$\begin{array}{c}\text { Flow } \\
\text { time } \\
{[\mathrm{s}]}\end{array}$} & \multirow[b]{2}{*}{$\begin{array}{c}\text { Plate } \\
\text { cohesion } \\
{[\mathrm{mm}]}\end{array}$} & \multirow[b]{2}{*}{$\begin{array}{l}\text { Density } \\
{\left[\mathrm{g} / \mathrm{cm}^{3}\right]}\end{array}$} & \multicolumn{3}{|c|}{ Rheological parameters } \\
\hline & & & & & $\begin{array}{c}\text { Static yield } \\
\text { stress } \\
{[\mathrm{Pa}]}\end{array}$ & $\begin{array}{c}\text { Dynamic } \\
\text { yield stress } \\
{[\mathrm{Pa}]}\end{array}$ & $\begin{array}{c}\text { Plastic } \\
\text { viscosity } \\
{[\mathrm{Pa} . \mathrm{s}]}\end{array}$ \\
\hline 1 & 125.5 & 24 & 0.458 & 2.13 & 11.7 & 64.2 & 2.22 \\
\hline 2 & 38 & NP & 0.001 & 1.97 & 1749.0 & NP & NP \\
\hline 3 & 200.5 & 17 & 0.250 & 2.16 & 5.6 & 0.4 & 1.33 \\
\hline 4 & 113.5 & 36 & 0.693 & 2.18 & 39.7 & 6.9 & 2.39 \\
\hline 5 & 123.5 & 28 & 0.535 & 2.13 & 25.2 & 4.5 & 2.77 \\
\hline 6 & 40 & NP & NP & 2.05 & 116.2 & NP & NP \\
\hline 7 & 184 & 23 & 0.498 & 2.16 & 8.6 & 0.1 & 1.66 \\
\hline 8 & 88 & 77 & 1.536 & 2.11 & 171.4 & 0.9 & 3.13 \\
\hline 9 & 116.5 & 27 & 0.553 & 2.15 & 40.8 & 28.1 & 2.72 \\
\hline 10 & 106.5 & 27 & 0.592 & 2.12 & 51.5 & 30.0 & 2.30 \\
\hline 11 & 112 & 31 & 0.521 & 2.11 & 43.7 & 34.8 & 2.87 \\
\hline
\end{tabular}

632

633 
635 Results of experimental work

\begin{tabular}{|c|c|c|c|c|c|c|c|c|c|}
\hline \multirow[b]{3}{*}{ Mix } & \multicolumn{5}{|c|}{ Heat of hydration } & \multicolumn{4}{|c|}{ Compressive strength } \\
\hline & $\mathrm{q}_{\max }$ & $\mathrm{t}\left(\mathrm{q}_{\max }\right)$ & $1-d$ & $3-d$ & $\begin{array}{c}\text { Induced } \\
\text { bleeding } \\
\text { at } 10 \\
\text { min }\end{array}$ & $\mathrm{f}_{\mathrm{c} 1 \mathrm{~d}}^{\prime} \mathrm{d}$ & $\mathrm{f}_{\mathrm{c} 3 \mathrm{~d}}^{\prime} \mathrm{d}$ & $\mathrm{f}_{\mathrm{c} 7 \mathrm{~d}}^{\prime} \mathrm{d}$ & $\mathrm{f}_{\mathrm{c} 28 \mathrm{~d}}^{\prime} \mathrm{d}$ \\
\hline & {$[\mathrm{W} / \mathrm{kg}]$} & [days] & {$[\mathrm{W} / \mathrm{kg}]$} & {$[\mathrm{W} / \mathrm{kg}]$} & {$[\mathrm{mL}]$} & [MPa] & {$[\mathrm{MPa}]$} & {$[\mathrm{MPa}]$} & [MPa] \\
\hline 1 & 2.432 & 0.70 & 1.184 & 0.256 & 20 & 22.5 & 49.3 & 61.8 & 73.6 \\
\hline 2 & 2.534 & 0.61 & 0.859 & 0.250 & 5.5 & 26.4 & 40.2 & 46.9 & 66.7 \\
\hline 3 & 2.089 & 1.08 & 1.936 & 0.283 & 3.5 & 9.2 & 47.4 & 69.6 & 83.1 \\
\hline 4 & 2.030 & 1.08 & 1.876 & 0.272 & 11.5 & 15.6 & 46.3 & 60.0 & 75.0 \\
\hline 5 & 2.083 & 0.76 & 1.274 & 0.210 & 21 & 22.8 & 50.1 & 55.0 & 77.7 \\
\hline 6 & 2.120 & 0.67 & 0.875 & 0.206 & 10 & 19.8 & 34.2 & 45.0 & 54.5 \\
\hline 7 & 1.728 & 1.25 & 0.909 & 0.262 & 4 & 5.6 & 44.2 & 57.3 & 75.4 \\
\hline 8 & 1.654 & 1.23 & 0.973 & 0.245 & 11.5 & 12.9 & 42.7 & 61.7 & 73.1 \\
\hline 9 & 2.047 & 1.02 & 2.042 & 0.244 & 13.5 & 16.4 & 50.3 & 63.7 & 80.6 \\
\hline 10 & 2.044 & 1.01 & 2.040 & 0.240 & 18 & 20.6 & 49.3 & 64.2 & 80.5 \\
\hline 11 & 2.041 & 1.01 & 2.039 & 0.239 & 17.5 & 20.8 & 49.2 & 63.6 & 76.5 \\
\hline
\end{tabular}

636

637 Table 7. Repeatability of test parameters at the central point

\begin{tabular}{|c|c|c|c|c|c|c|c|c|}
\hline Tests & $\begin{array}{l}\text { Mini- } \\
\text { slump }\end{array}$ & $\begin{array}{l}\text { Marsh } \\
\text { cone }\end{array}$ & $\begin{array}{c}\text { Plate } \\
\text { cohesion }\end{array}$ & $\begin{array}{l}\text { Static } \\
\text { yield }\end{array}$ & $\begin{array}{l}\text { Yield } \\
\text { stress }\end{array}$ & $\begin{array}{c}\text { Plastic } \\
\text { viscosity }\end{array}$ & $\mathrm{q}_{\max }$ & $\begin{array}{l}\text { Induced } \\
\text { bleeding }\end{array}$ \\
\hline \multirow{2}{*}{ Mean $(n=3)$} & 111.7 & 28.3 & 0.56 & 45.3 & 31 & 2.6 & 2.044 & \multirow{2}{*}{$\begin{array}{r}16 \\
\mathrm{~mL}\end{array}$} \\
\hline & $\mathrm{mm}$ & $\mathrm{s}$ & $\mathrm{mm}$ & $\mathrm{Pa}$ & $\mathrm{Pa}$ & $\mathrm{Pa} \mathrm{s}$ & $\mathrm{W} / \mathrm{kg}$ & \\
\hline $\begin{array}{l}\text { Coefficient of } \\
\text { variation (\%) }\end{array}$ & 4.5 & 8.2 & 6.4 & 12.2 & 11.2 & 11.2 & 0.147 & 15 \\
\hline \multirow{2}{*}{$\begin{array}{c}\text { Estimate error } \\
(90 \% \\
\text { confidence } \\
\text { limit })\end{array}$} & 5.5 & 2.5 & 0.04 & 6.0 & 3.8 & 0.3 & \multirow{2}{*}{0.003} & \multirow[t]{2}{*}{$2.7 \mathrm{~mL}$} \\
\hline & $\mathrm{mm}$ & s & $\mathrm{mm}$ & $\mathrm{Pa}$ & $\mathrm{Pa}$ & $\mathrm{Pa} \mathrm{s}$ & & \\
\hline Tests & $\mathrm{t}(\mathrm{qmax})$ & 1d-heat & 3d-heat & $f_{c 1 \mathrm{~d}}^{\prime}$ & $f_{c 3 \mathrm{~d}}^{\prime}$ & $f_{c 7 \mathrm{~d}}^{\prime}$ & $f^{\prime} c_{228 \mathrm{~d}}$ & \\
\hline Mean $(n=3)$ & $\begin{array}{c}1.01 \\
\mathrm{~d}\end{array}$ & $\begin{array}{c}2.04 \\
(\mathrm{~W} / \mathrm{kg})\end{array}$ & $\begin{array}{c}0.241 \\
(\mathrm{~W} / \mathrm{kg})\end{array}$ & $\begin{array}{c}19.3 \\
(\mathrm{MPa})\end{array}$ & $\begin{array}{c}49.6 \\
(\mathrm{MPa})\end{array}$ & $\begin{array}{c}63.8 \\
(\mathrm{MPa})\end{array}$ & $\begin{array}{c}79.2 \\
(\mathrm{MPa})\end{array}$ & \\
\hline $\begin{array}{l}\text { Coefficient of } \\
\text { variation }(\%)\end{array}$ & 0.6 & 6 & 1.10 & 13 & 1.2 & 0.5 & 3.0 & \\
\hline Estimate error & 0.001 & 0.002 & 0.003 & 2.7 & 0.7 & 0.4 & 2.5 & \\
\hline limit) & d & $\mathrm{W} / \mathrm{kg}$ & $\mathrm{W} / \mathrm{kg}$ & $\mathrm{MPa}$ & $\mathrm{MPa}$ & $\mathrm{MPa}$ & $\mathrm{MPa}$ & \\
\hline
\end{tabular}


639 Table 8

640 Comparison of results on compressive of paste and mortar at $1 \mathrm{~d}$ and $7 \mathrm{~d}$

\begin{tabular}{lcccc}
\hline & $\begin{array}{c}\text { Paste } 1 \\
1 \mathrm{~d}\end{array}$ & $\begin{array}{c}\text { Paste } 2 \\
1 \mathrm{~d}\end{array}$ & $\begin{array}{c}\text { Paste } 1 \\
7 \mathrm{~d}\end{array}$ & $\begin{array}{c}\text { Paste } 2 \\
7 \mathrm{~d}\end{array}$ \\
\hline $\mathrm{f}^{\prime}{ }_{\mathrm{c}}[\mathrm{MPa}]$ & 15.6 & 17.1 & 51.1 & 52.3 \\
\hline & Mortar 1 & Mortar 2 & Mortar 1 & Mortar 2 \\
& $1 \mathrm{~d}$ & $1 \mathrm{~d}$ & $7 \mathrm{~d}$ & $7 \mathrm{~d}$ \\
\hline $\mathrm{f}^{\prime}{ }_{\mathrm{c}}[\mathrm{MPa}]$ & 22.5 & 26.4 & 61.8 & 46.9
\end{tabular}

641

642 Table 9

643 Mineral composition of pastes

\begin{tabular}{lcccc}
\hline$[\%]$ & Paste 1 & Paste 2 & Paste 1 & Paste 2 \\
$1 \mathrm{~d}$ & $1 \mathrm{~d}$ & $7 \mathrm{~d}$ & $7 \mathrm{~d}$ \\
\hline $\mathrm{C}_{2} \mathrm{~S}$ & 6.3 & 7.1 & 5.6 & 5.1 \\
$\mathrm{C}_{3} \mathrm{~S}$ & 19.6 & 18.4 & 4.5 & 5.2 \\
$\mathrm{C}_{3} \mathrm{~A}$ & 2 & 1.3 & 0 & 0 \\
$\mathrm{C}_{4} \mathrm{AF}$ & 4.1 & 4.2 & 1.5 & 1.6 \\
$\mathrm{AFt}$ & 8.4 & 8.6 & 6.4 & 6.3 \\
$\mathrm{CH}$ & 9.9 & 10.7 & 14.9 & 15.9 \\
$\mathrm{Calcite}$ & 6.1 & 5.8 & 4.3 & 3.6 \\
Quartz & 0.6 & 0.6 & 1.1 & 0.8 \\
Semicarbonate & $/$ & 0.1 & 2.3 & 2.5 \\
Amorphous & 42.9 & 43.2 & 59.3 & 59 \\
\hline
\end{tabular}

$644 \mathrm{C}_{2} \mathrm{~S}$ : Dicalcium silicate, $\mathrm{C}_{3} \mathrm{~S}$ : Tricalcium silicate, $\mathrm{C}_{3} \mathrm{~A}$ : Tricalcium aluminate, $\mathrm{C}_{4} \mathrm{AF}$ :

645 Tetracalcium ferroaluminate, AFt: most common AFt phase is ettringite, $\mathrm{CH}$ : Portlandite 
Criteria, goals and goals' importance used in desirability (numerical optimization)

\begin{tabular}{|c|c|c|c|c|}
\hline \multirow[b]{2}{*}{ Criteria } & \multicolumn{2}{|c|}{ Example 1} & \multicolumn{2}{|c|}{ Example 2} \\
\hline & $\begin{array}{c}\text { Goal/ } \\
\text { Importance }\end{array}$ & $\begin{array}{c}\text { Solution }= \\
0.649\end{array}$ & $\begin{array}{c}\text { Goal/ } \\
\text { Importance }\end{array}$ & $\begin{array}{c}\text { Solution }= \\
0.633\end{array}$ \\
\hline \multicolumn{5}{|l|}{ Factors } \\
\hline $\mathrm{nCL}[\%]$ & In range/NA & 1.36 & Minimise 1 & 0.5 \\
\hline $\mathrm{SP}[\%]$ & In range/NA & 3.0 & Minimise 1 & 1.8 \\
\hline FA $[\%]$ & In range/NA & 5.0 & In range/NA & 8.9 \\
\hline \multicolumn{5}{|l|}{ Responses } \\
\hline Mini-slump flow [mm] & Maximise 5 & 164 & Maximise 5 & 161 \\
\hline Marsh cone $[\mathrm{s}]$ & Minimise 1 & 21.7 & Minimise 1 & 21.3 \\
\hline Plate cohesion [mm] & Minimise 1 & 0.42 & Minimise 1 & 0.36 \\
\hline Dynamic yield stress [Pa] & Minimise 1 & 3.2 & Minimise 1 & 16.3 \\
\hline Plastic viscosity [Pa.s] & Minimise 1 & 1.7 & Minimise 1 & 1.8 \\
\hline Induced bleeding $10 \mathrm{~min}[\mathrm{ml}]$ & Minimise 1 & 6.3 & Minimise 1 & 11.7 \\
\hline Heat of hydration at $1 \mathrm{~d}$ & In range & 1.9 & In range & 1.44 \\
\hline Heat of hydration at $3 \mathrm{~d}$ & In range & 0.28 & In range & 0.26 \\
\hline $\mathrm{f}_{\mathrm{cld}}^{\prime}[\mathrm{MPa}]$ & Maximise 5 & 11.9 & Maximise 5 & 15.7 \\
\hline $\mathrm{f}_{\mathrm{c} 3 \mathrm{~d}}^{\prime}[\mathrm{MPa}]$ & Maximise 5 & 46.9 & Maximise 5 & 48.0 \\
\hline $\mathrm{f}_{\mathrm{c} 7 \mathrm{~d}}^{\prime}[\mathrm{MPa}]$ & Maximise 5 & 65.1 & Maximise 5 & 63.3 \\
\hline $\mathrm{f}^{\prime}{ }_{\mathrm{c} 28 \mathrm{~d}}[\mathrm{MPa}]$ & Maximise 5 & 79.6 & Maximise 5 & 79.6 \\
\hline
\end{tabular}



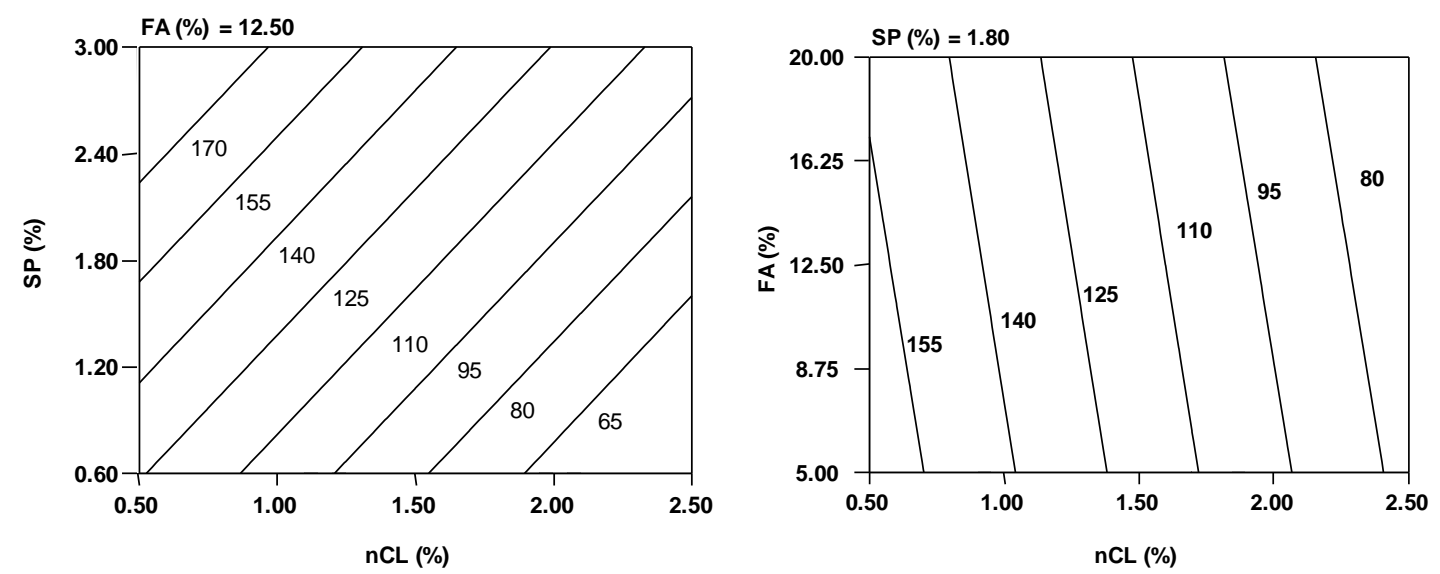

655

656

657

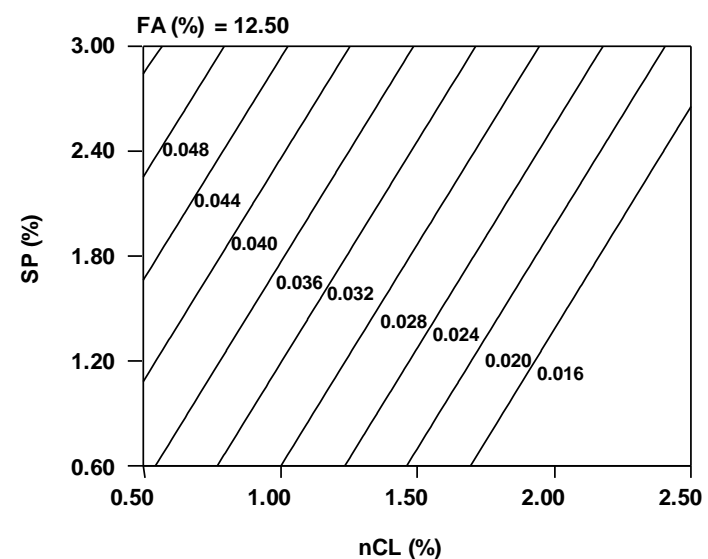

658

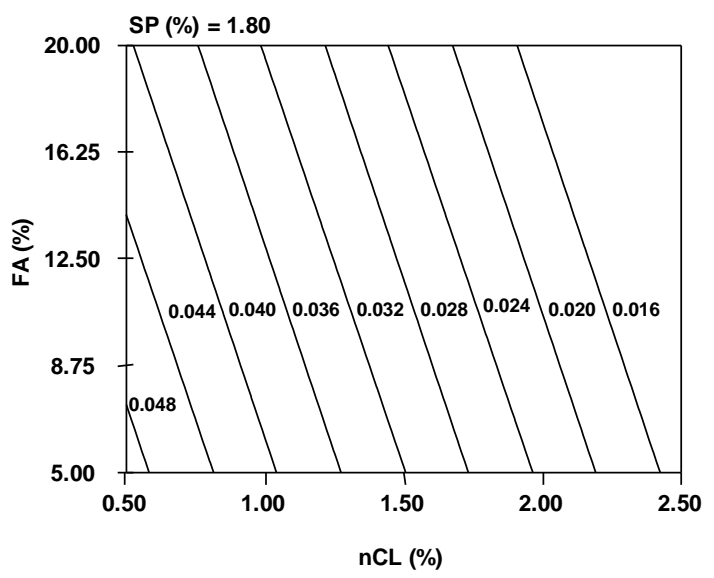

$\mathrm{nCL}(\%)$
659

660

661

662

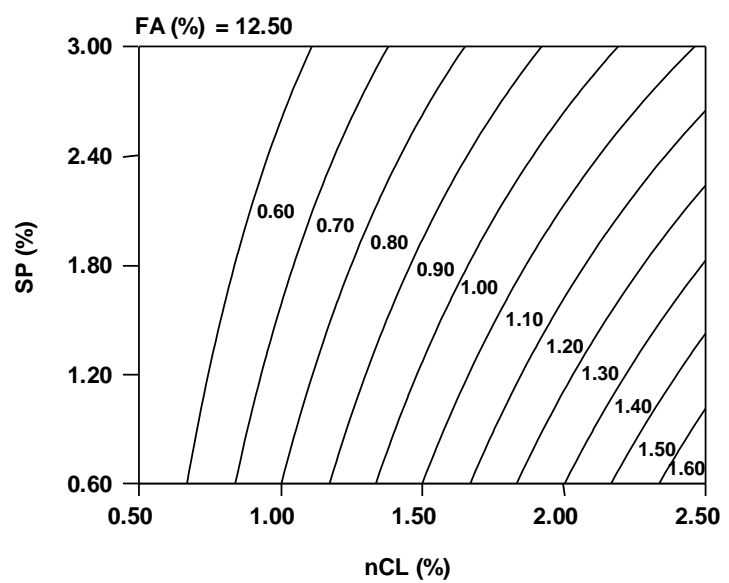

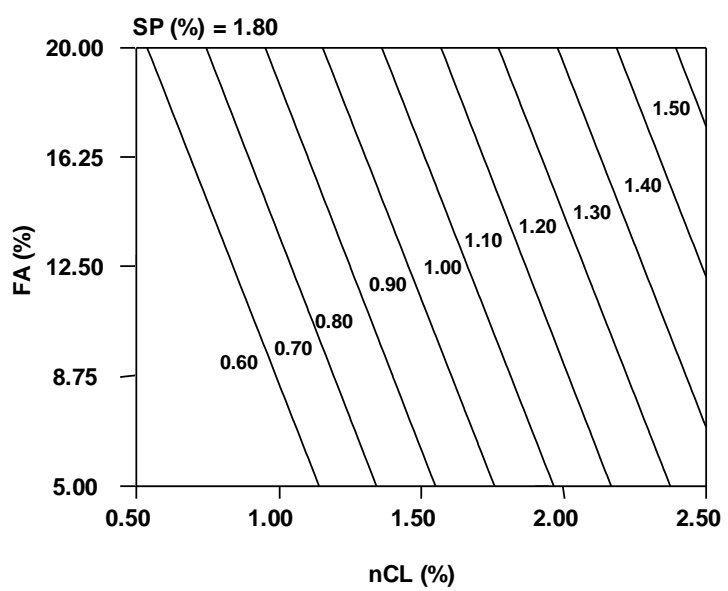

Fig. 3. Isoresponse curve of plate cohesion (a) nCL versus SP, (b) nCL versus FA 

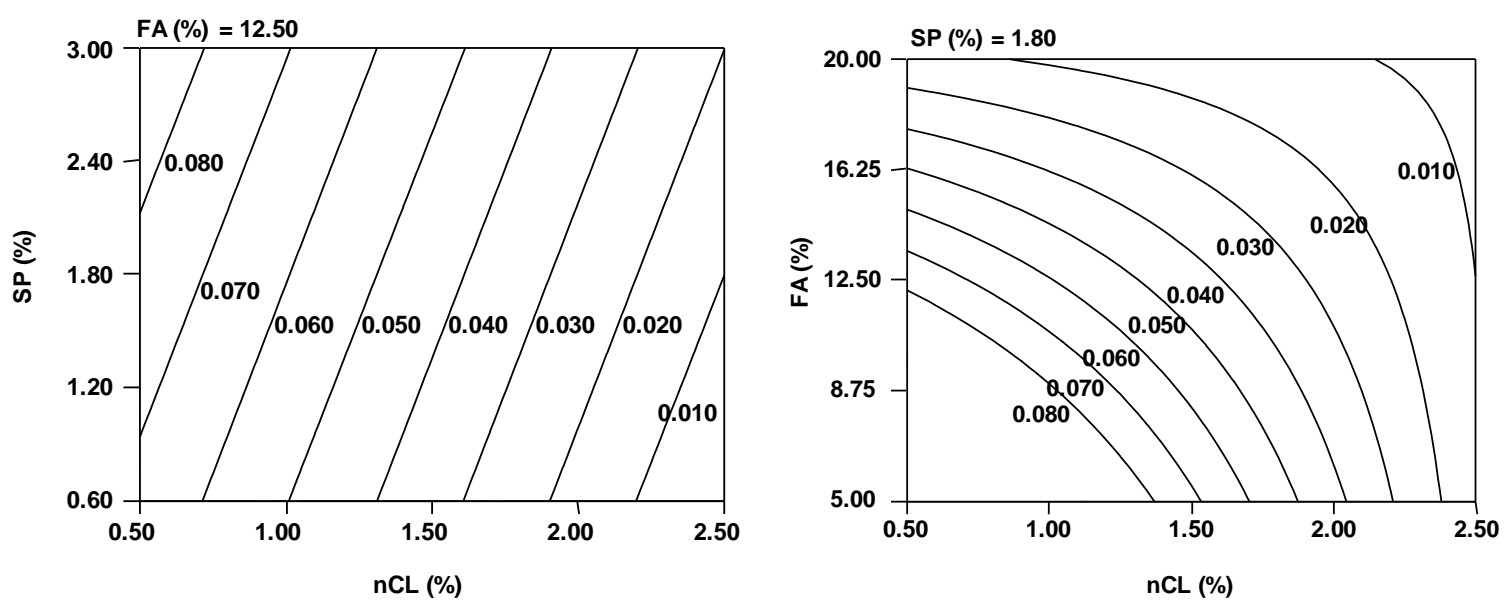

665

Fig. 4. Isoresponse curve of $1 /$ static yield stress (a) nCL versus SP, (b) nCL versus FA 667
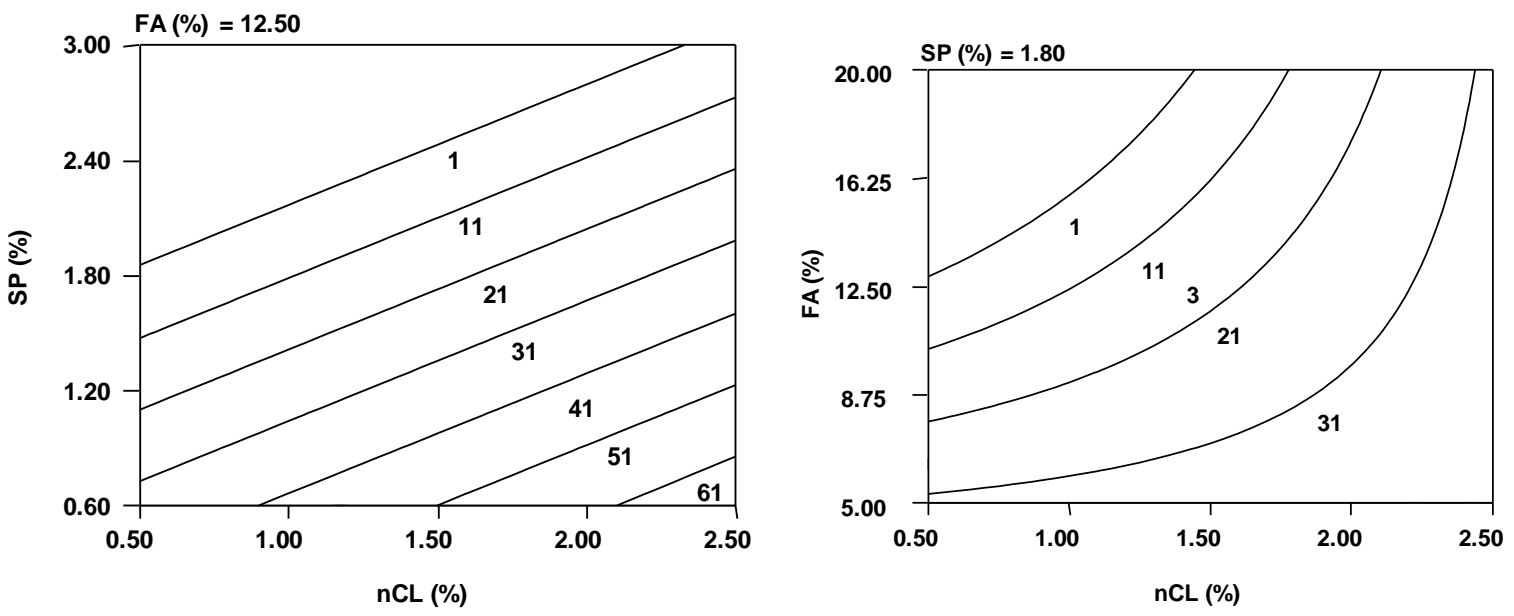

669

Fig. 5. Isoresponse curve of dynamic yield stress (a) nCL versus SP, (b) nCL versus FA 670
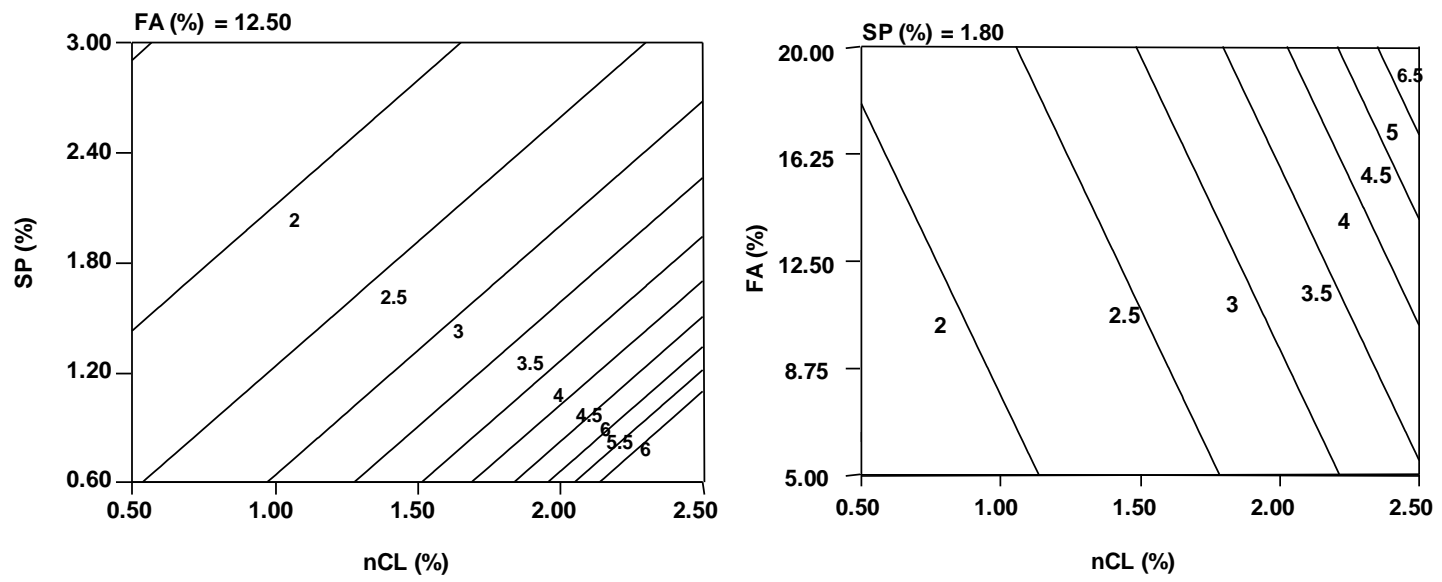

$\mathrm{nCL}(\%)$

Fig. 6. Isoresponse curve of plastic viscosity (a) nCL versus SP, (b) nCL versus FA 

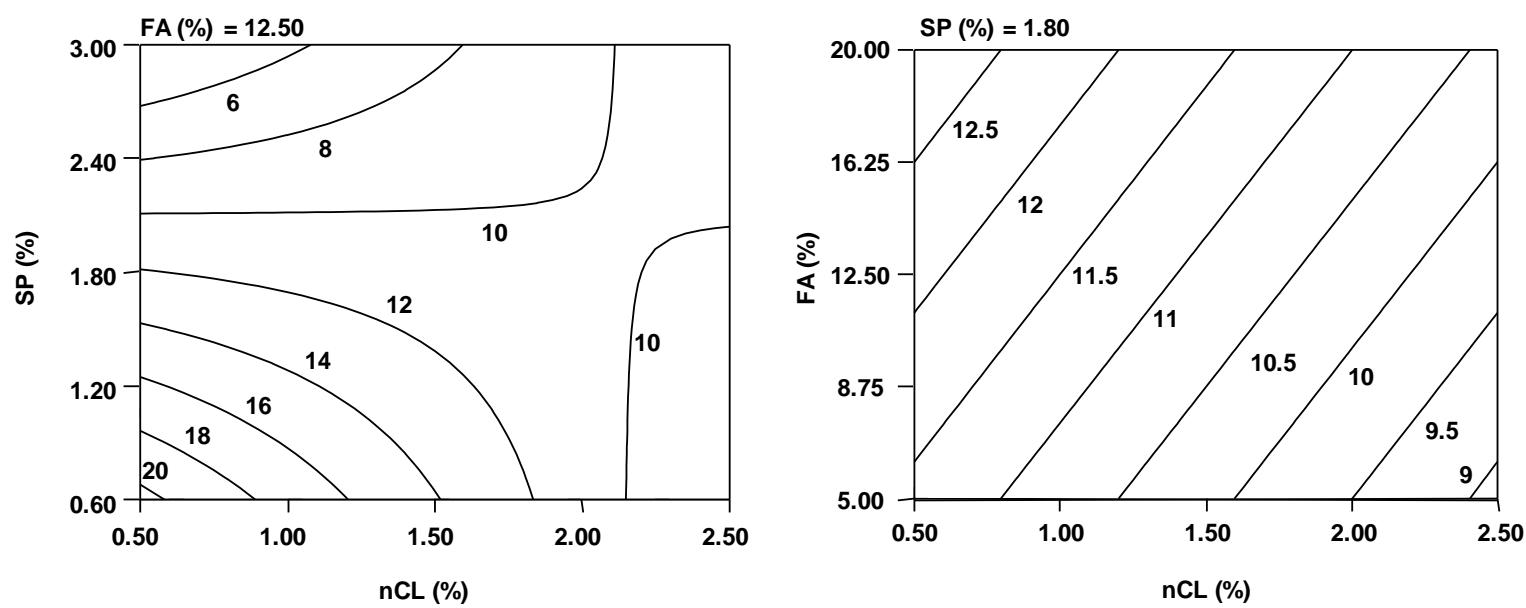

674 Fig. 7. Isoresponse curve of Induced bleeding at $10 \mathrm{~min}$ a) nCL versus SP, (b) nCL versus 675 FA

676
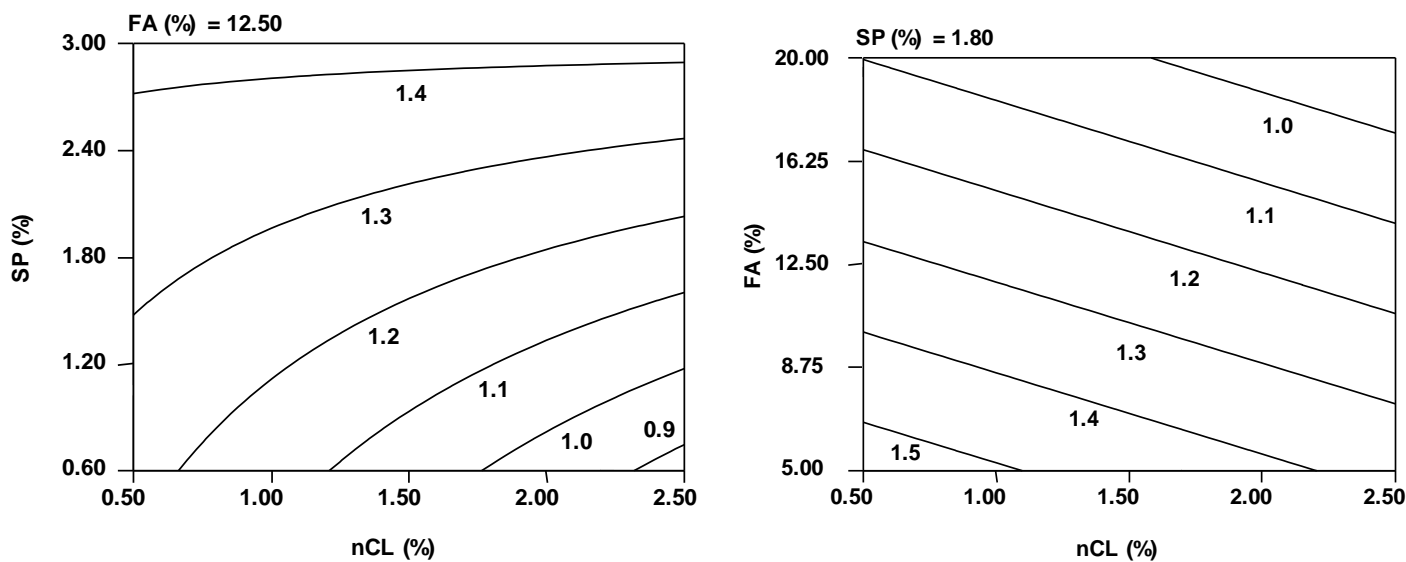

677 $\mathrm{nCL}(\%)$

678 Fig. 8. Isoresponse curve of heat of hydration at $1 \mathrm{~d}$ (a) nCL versus SP, (b) nCL versus FA 679
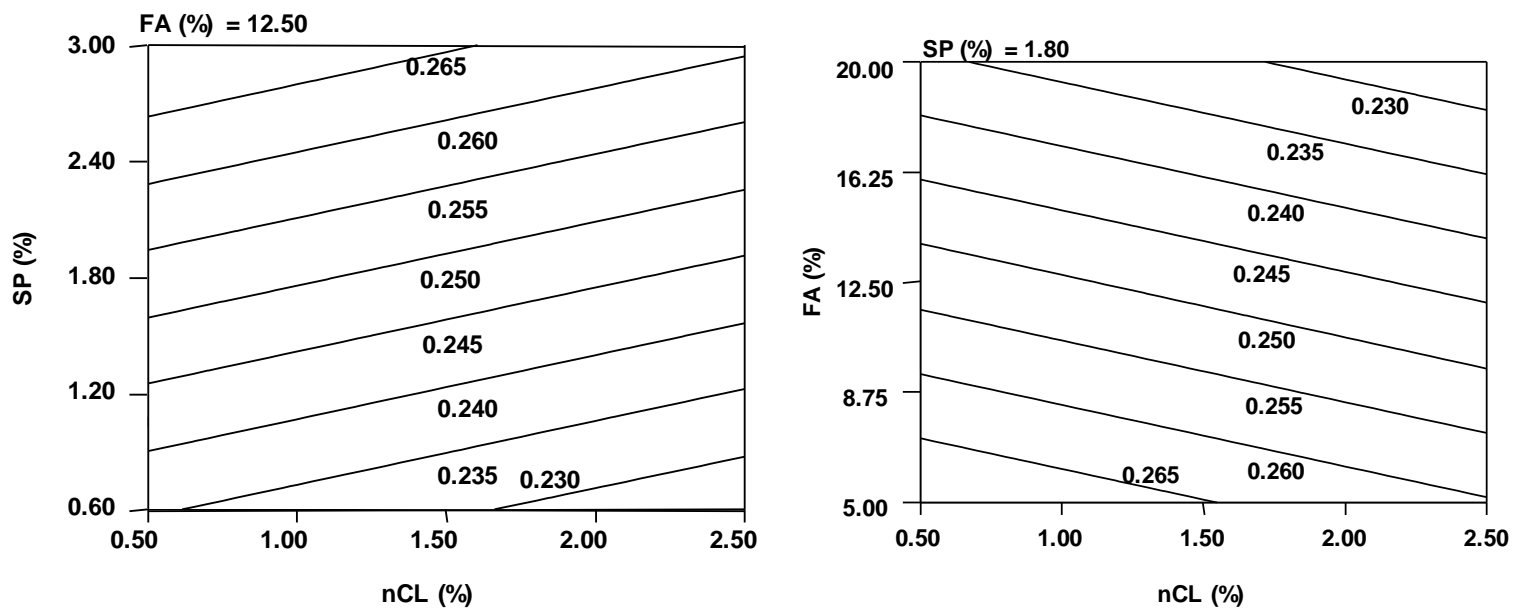

Fig. 9. Isoresponse curve of heat of hydration at $3 \mathrm{~d}$ (a) nCL versus $\mathrm{SP}$, (b) nCL versus FA 


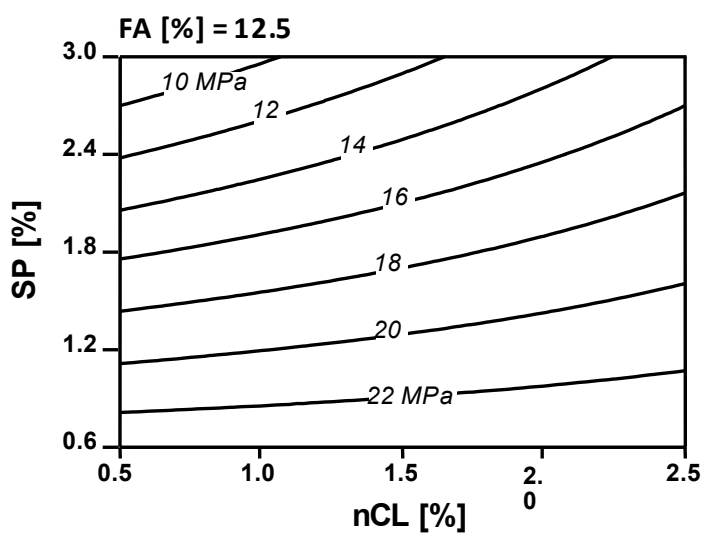

(a) 1 day

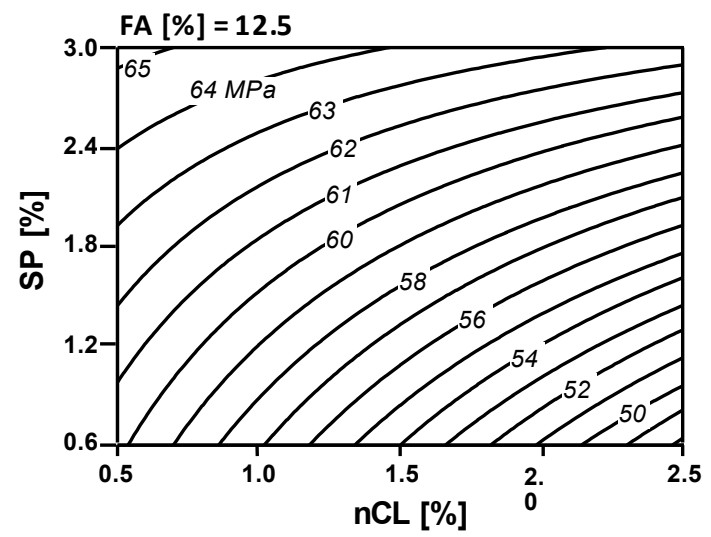

(c) 7 days

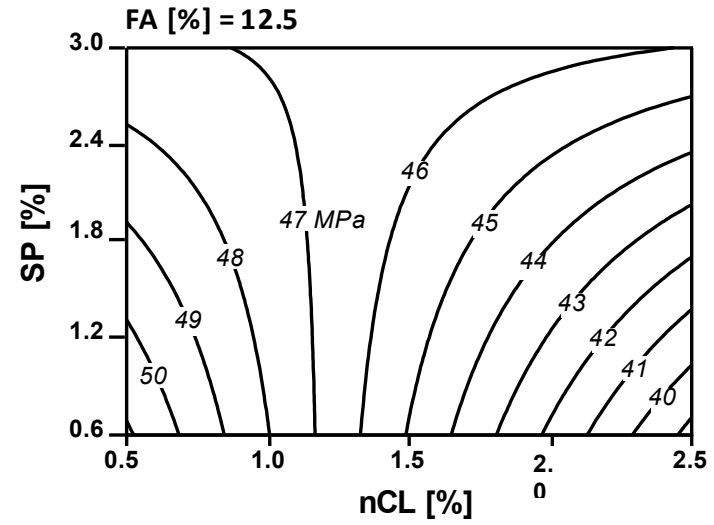

(b) 3 days

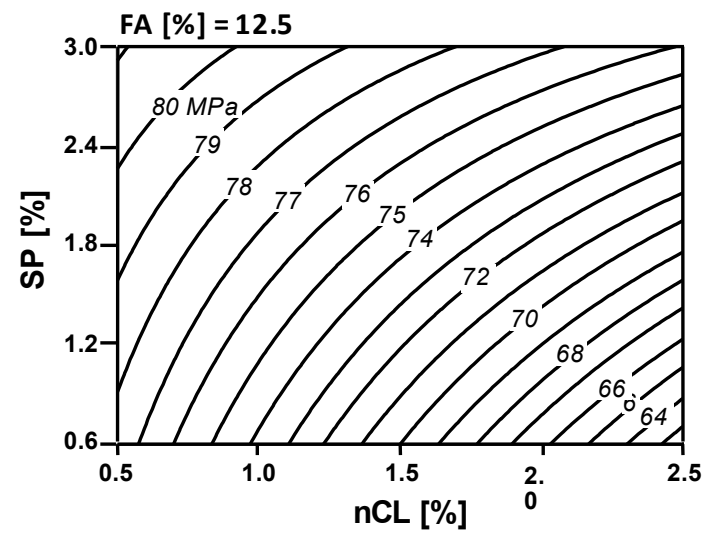

(d) 28 days
684

685

686

687

688
Fig. 10. Isoresponse curves for the compressive strengths at 1, 3, 7 and 28 days (nCL versus $\mathrm{SP})$ 


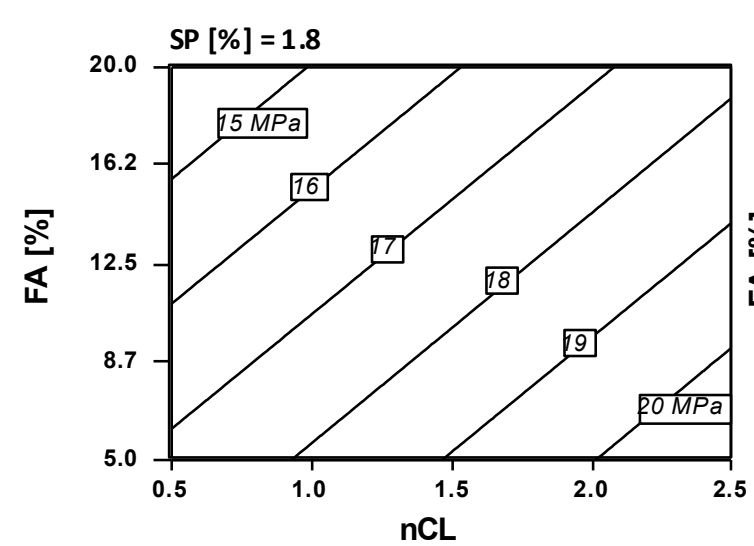

(a) 1 day

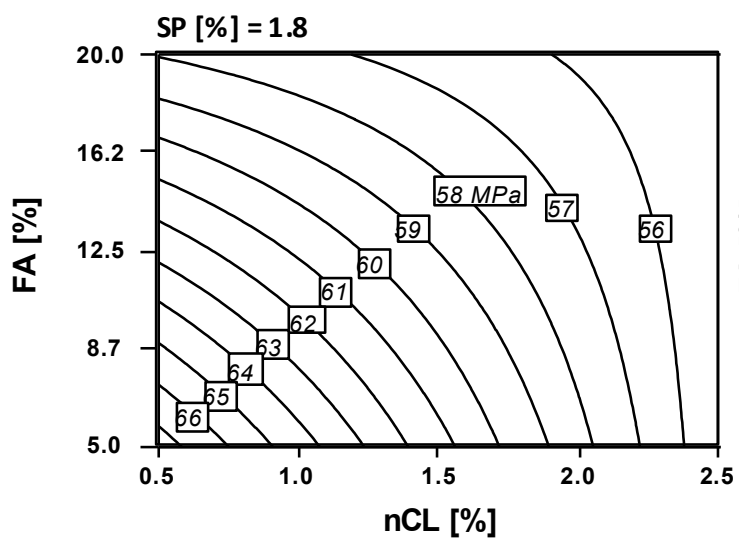

(c) 7 days

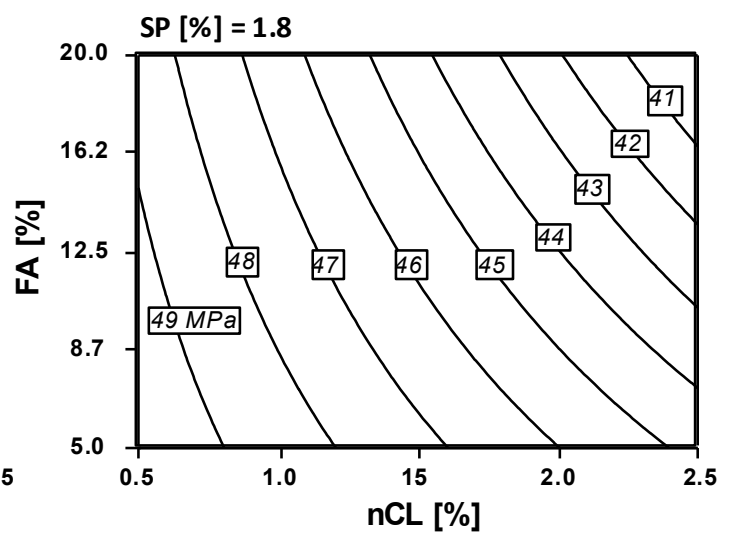

(b) 3 days

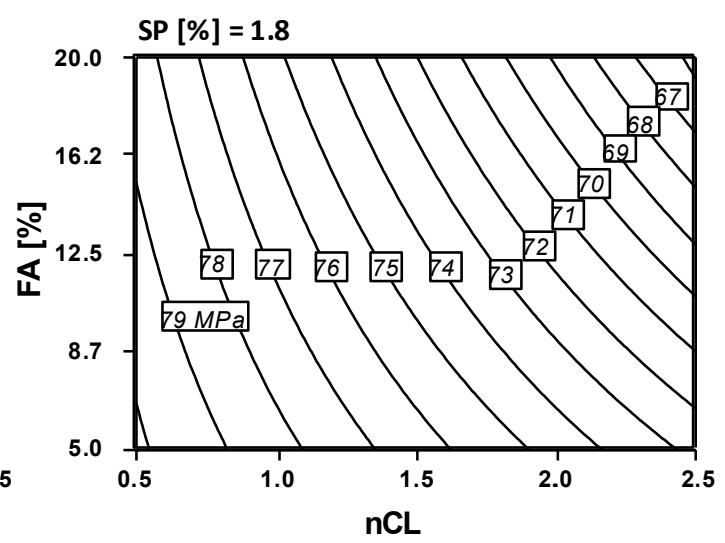

(d) 28 days
689

690

691

692
Fig. 11. Isoresponse curves for compressive strengths at $1 \mathrm{~d}, 3 \mathrm{~d}, 7 \mathrm{~d}$ and $28 \mathrm{~d}$ (nCL versus FA) 
counts

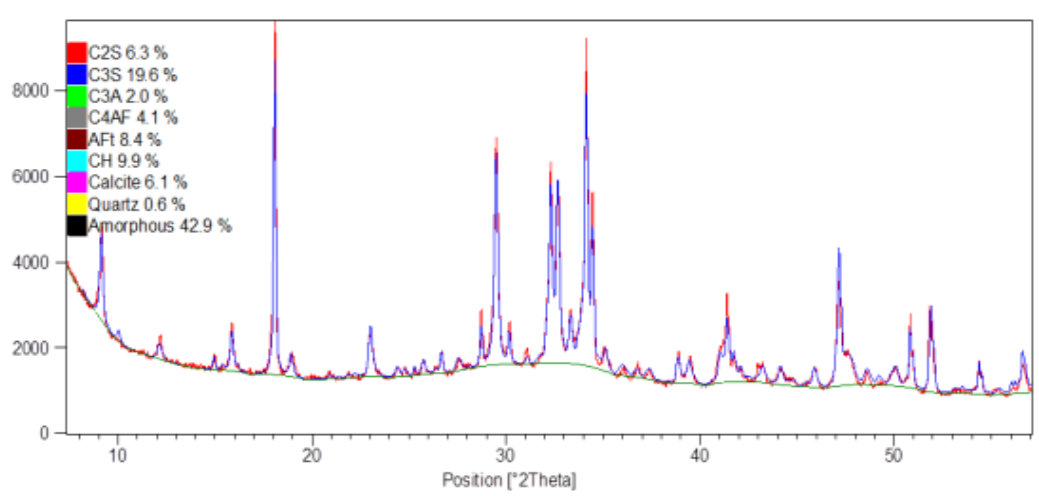

694

695 (a) Mix 1(0.50\% nCL, 0.60\% SP, 5\% FA) $1 d$

696

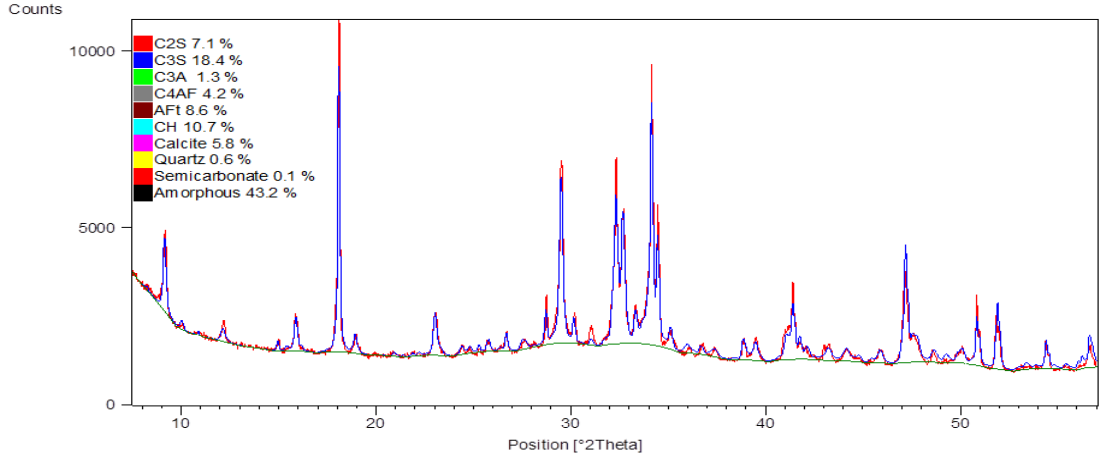

697 (b) Mix $2(2.50 \%$ nCL, $0.60 \%$ SP, $5 \%$ FA) $1 d$

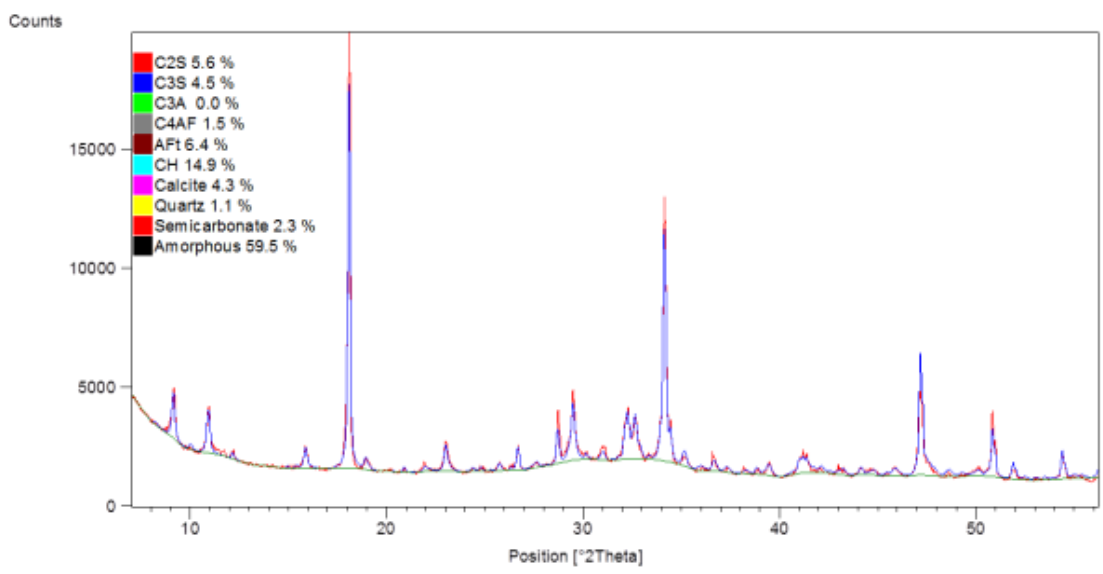

698

699 (c) (a) Mix $1(0.50 \% \mathrm{nCL}, 0.60 \%$ SP, $5 \%$ FA 7 days 


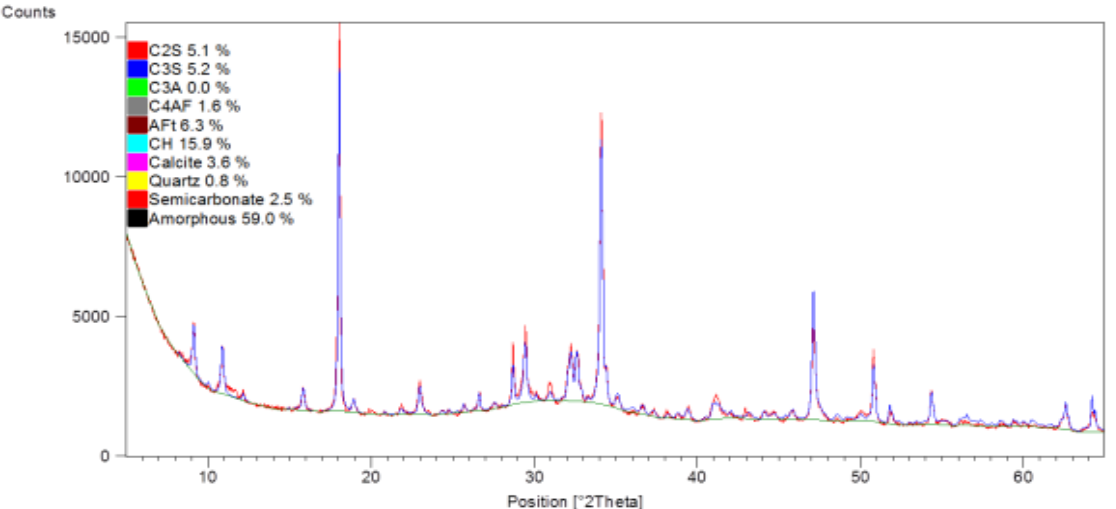

700

701 (d) Mix 2 (2.50\% nCL, 0.60\% SP, 5\% FA) 7 days 


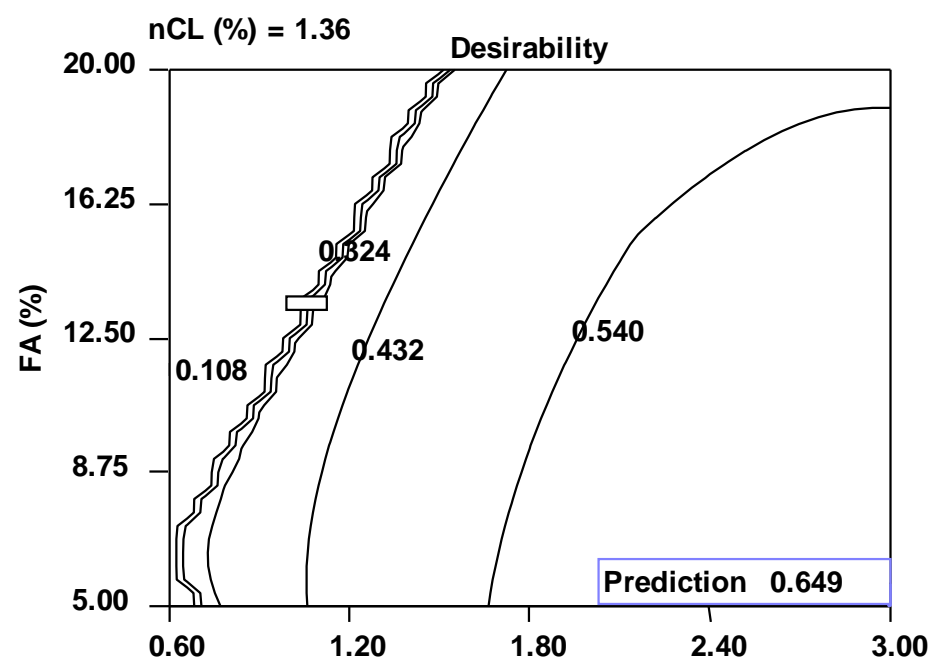

705

708

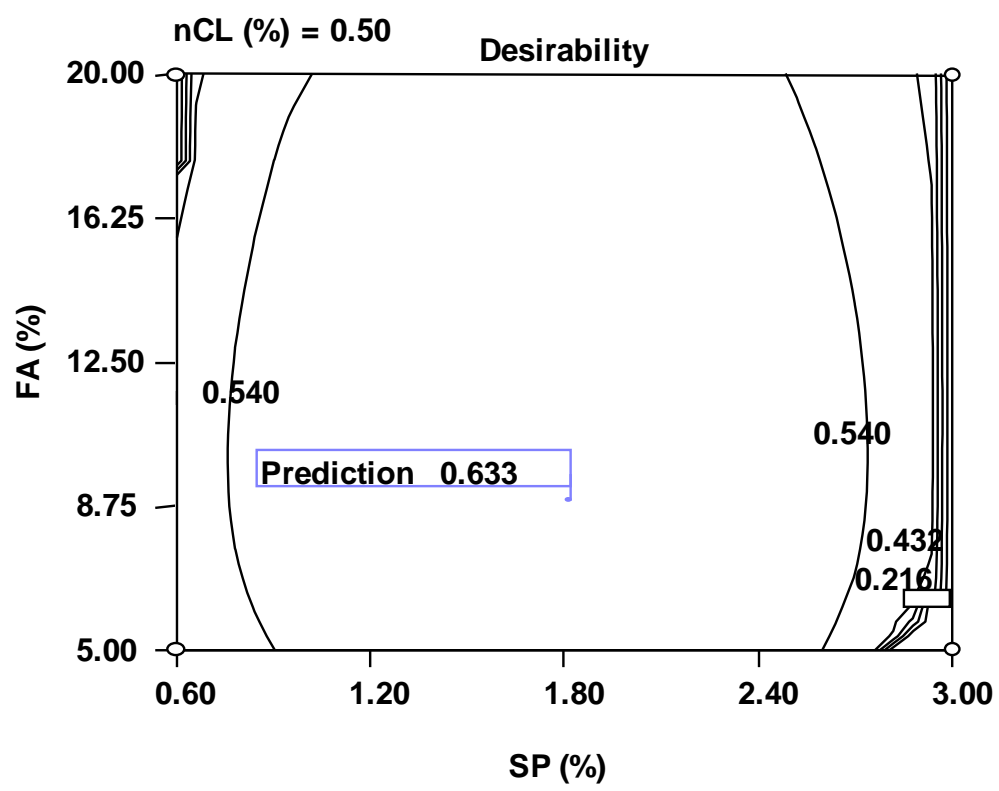

Fig. 14. Contour plots of the desirability function based on multi-parametric optimisation (Example 2). 
